\title{
Potential of the dual mTOR kinase inhibitor AZD2014 to overcome paclitaxel resistance in anaplastic thyroid carcinoma
}

\author{
Zorica Milošević ${ }^{1}$ Jasna Banković ${ }^{1}$ Jelena Dinić ${ }^{1} \cdot$ Chrisiida Tsimplouli $^{2} \cdot$ Evangelia Sereti $^{2} \cdot$ Miodrag Dragoj $^{1}$. \\ Verica Paunović ${ }^{3}$ - Zorka Milovanović ${ }^{4}$ Marija Stepanović ${ }^{1} \cdot$ Nikola Tanić $^{1} \cdot$ Kostantinos Dimas $^{2} \cdot$ Milica Pešić $^{1}$ (D)
}

Accepted: 23 April 2018 / Published online: 22 May 2018

(C) International Society for Cellular Oncology 2018

\begin{abstract}
Purpose Anaplastic thyroid carcinoma (ATC) is an aggressive, chemo-resistant malignancy. Chemo-resistance is often associated with changes in activity of the RAS/MAPK/ERK and PI3K/AKT/mTOR pathways and/or a high expression of ATP binding cassette (ABC) transporters, such as P-glycoprotein (P-gp) and breast cancer resistance protein (BCRP). To assess the therapeutic efficacy in ATC of a combination of the dual mTOR kinase inhibitor vistusertib (AZD2014) and paclitaxel (PTX), we generated a new cell line (Rho-) via the selection of human thyroid carcinoma $8505 \mathrm{C}$ cells that exhibit a low accumulation of rhodamine 123, which serves as a P-gp and BCRP substrate.

Methods Immunohistochemistry was used for P-gp and BCRP expression analyses in primary ATC patient samples. Spheroid formation and immunodeficient NSG mice were used for performing in vitro and in vivo tumorigenicity assays, respectively. MTT, flow-cytometry, fluorescent microscopy, cell death and proliferation assays, as well as migration, invasion and gelatin degradation assays, were used to assess the potential of AZD2014 to enhance the effects of PTX. ATC xenografts in SCID mice were used for evaluating in vivo treatment efficacies.

Results Rho- cells were found to be 10 -fold more resistant to PTX than $8505 \mathrm{C}$ cells and, in addition, to be more tumorigenic. We also found that AZD2014 sensitized Rho- cells to PTX by inhibiting proliferation and by inducing autophagy. The combined use of AZD2014 and PTX efficiently inhibited in vitro ATC cell migration and invasion. Subsequent in vivo xenograft studies indicated that the AZD2014 and PTX combination effectively suppressed ATC tumor growth.

Conclusions Our data support results from recent phase I clinical trials using combinations of AZD2014 and PTX for the treatment of solid tumors. Such combinations may also be employed for the design of novel targeted ATC treatment strategies.
\end{abstract}

Keywords Anaplastic thyroid carcinoma $\cdot$ mTOR $\cdot$ AZD2014 $\cdot$ Paclitaxel $\cdot$ Chemo-resistance $\cdot$ Targeted therapy

Electronic supplementary material The online version of this article (https://doi.org/10.1007/s13402-018-0380-x) contains supplementary material, which is available to authorized users.

Milica Pešić

camala@ibiss.bg.ac.rs

1 Institute for Biological Research "Siniša Stanković", University of Belgrade, Despota Stefana 142, Belgrade 11060, Serbia

2 Department of Pharmacology, Faculty of Medicine, School of Health Sciences, University of Thessaly, Biopolis, 41110 Larissa, Greece

3 Institute of Microbiology and Immunology, School of Medicine, University of Belgrade, Dr. Subotića 1, Belgrade 11000, Serbia

4 Institute for Oncology and Radiology of Serbia, Pasterova 14, Belgrade 11000, Serbia

\section{Introduction}

Anaplastic thyroid carcinoma (ATC), one of the most aggressive human malignancies, has a very poor prognosis. The overall median survival is limited to months [1]. Although ATC accounts for only $0.8 \%$ of all thyroid cancers, its disease-specific mortality approaches $100 \%$ [2, 3]. It has been found that surgery, radiotherapy and chemotherapy fail to significantly improve the survival of patients [4]. Current chemotherapy protocols include doxorubicin (DOX) and paclitaxel (PTX), whereas cisplatin (CPt) has been removed from them [5]. To improve the clinical outcome, it is important to explore more thoroughly the molecular mechanisms underlying ATC development. As more of these data become available, more targeted drugs may be considered for therapy. To this end, 
small-molecule tyrosine kinase inhibitors, angiogenesis inhibitors and vascularization disrupting agents have already been investigated [6].

Most ATCs harbor mutations that activate the RAS/ MAPK/ERK and/or PI3K/AKT/mTOR pathways [7]. These signaling pathways control cellular survival, differentiation, proliferation and metabolism [8]. Changes in the activity of these signaling pathways may lead to drug resistance [9], which is a common feature of ATC. Previously, we reported that either the RAS/MAPK/ERK or the PI3K/AKT/mTOR pathway may underlie the development of ATC [10]. We also showed that inhibition of either RAS/MAPK/ERK or $\mathrm{PI} 3 \mathrm{~K} / \mathrm{AKT} / \mathrm{mTOR}$ pathway components may serve as valuable therapeutic approaches for ATC. Interestingly, we found that inhibition of RAS/MAPK/ERK signaling sensitized ATC cells to PTX, whereas inhibition of the PI3K/AKT/mTOR pathway led to a higher susceptibility of ATC cells to DOX. We also found that application of the dual mTOR kinase inhibitor vistusertib (AZD2014) was highly effective, since it equally sensitized ATC cells to DOX and PTX [10].

mTOR is a highly conserved protein kinase to which both the RAS/MAPK/ERK and the PI3K/AKT/mTOR signaling pathways converge. Its activation has been found to promote cell cycle progression and to suppress apoptosis in a variety of human cancers [11]. mTOR can be found in two structurally and functionally distinct multiprotein complexes, i.e., mTOR complex 1 (mTORC1) and mTOR complex 2 (mTORC2). These complexes encompass different components, among which the most significant component for mTORC1 is raptor, while that for mTORC2 is rictor [12]. Increased mTOR activity in cancers often results from mutations in closely related pathways. As such, amplification of the PIK3CA gene (encoding the p110a subunit of PI3K) can constitutively activate mTOR [13]. Also, loss or inactivation of PTEN, which inhibits PI3K, and mutations of negative regulators of mTOR, such as the tuberous sclerosis 1 and 2 complexes (TSC1 and TSC2), p53 and LKB1, may induce mTOR activation [14]. More recently, also activating mutations in mTOR itself have been identified [15]. Activation of the PI3K/AKT/mTOR pathway has been shown to correlate with tumor progression and a reduced survival in patients harboring a variety of tumor types, including ATC $[16,17]$. Therefore, mTOR inhibition is currently a focus of many anticancer studies and clinical trials [18, 19]. Rapamycin belongs to the first generation of mTOR inhibitors. It is an allosteric inhibitor that prevents mTOR-dependent downstream signal transduction. mTORC1 is rapamycin sensitive while mTORC2 is relatively rapamycin insensitive. Limitations of rapamycin-based therapies in clinical settings have led to the development of a second generation of mTOR inhibitors, known as ATP-competitive mTOR kinase inhibitors. These inhibitors target the ATP-binding pocket of the kinase domain of mTOR and, by doing so, inhibit its catalytic activity. The mechanistic advantage of these agents is their potential to inhibit the kinase activities of both the mTORC1 and mTORC2 complexes, along with blocking the feedback activation of PI3K/Akt signaling [20, 21]. One of the representatives of this class of inhibitors is AZD2014, which is currently in clinical trials for several solid tumors [22, 23]. Although we recently showed that AZD2014 has the potential to overcome ATC chemo-resistance [10], the investigation of mTOR inhibition in ATC is still in a preliminary stage.

Another mechanism underlying ATC chemo-resistance involves the overexpression of $\mathrm{ABC}$ transporters responsible for the development of multidrug resistance. Multidrug resistance (MDR) confers resistance to cancer cells against a variety of structurally and functionally unrelated anticancer drugs [24]. In most MDR cells, drug efflux is mediated by the ATP-binding cassette $(\mathrm{ABC})$ membrane transporter P-glycoprotein (P-gp/ MDR1/ABCB1), which is encoded by the MDR1 gene [25]. Since more than 30 years P-gp has been the most studied ABC transporter [26]. Other $\mathrm{ABC}$ transporters, such as the multidrug resistance protein 1 (MRP1/ABCC1) [27, 28] and the breast cancer resistance protein (BCRP/ABCG2), are also known to be involved in MDR [29]. As of yet, the contribution of these transporters in ATC chemo-resistance has not been studied.

The aim of this study was to determine the potential of the dual mTOR kinase inhibitor AZD2014 to overcome chemoresistance in ATC cells overexpressing MDR transporters. To this end, we established a new ATC cell line resistant to PTX and employed this cell line to determine the efficacy of AZD2014, alone or in combination with PTX, both in vitro and in vivo.

\section{Materials and methods}

\subsection{Tissue samples}

Primary ATC tissue samples from 12 patients who underwent surgical resection at the Institute for Oncology, Clinical Center of Serbia, were collected. Informed consents and approval from the Ethics Committee were obtained in accordance with the standards laid down in the 1964 Declaration of Helsinki. The ATC tissues were fixed in $10 \%$ buffered formalin and embedded in paraffin. The diagnosis of ATC was established by histologic examination. The selected patients included 8 women and 4 men, with a median age of 67.2 years (range: 46-82 years). The surgeries performed were mainly palliative in nature, and the median patient survival period was 68 days (35-441 days). The patients received neither radiotherapy nor chemotherapy prior to surgery.

\subsection{Immunohistochemistry}

The formalin-fixed paraffin-embedded (FFPE) ATC tissues were cut in 3- $\mu \mathrm{m}$ sections for further analysis. Anti-P-gp 
(1:40, Abcam, United Kingdom) and anti-BCRP (1:40, Abcam, United Kingdom) antibodies were used according to the manufacturer's instructions. Immunostaining was performed by incubating the tissue sections for $30 \mathrm{~min}$ at room temperature in a humidity chamber using the streptavidinbiotin technique (LSAB+ Kit, Peroxidase Labeling, K0690; DakoCytomation, Glostrup, Denmark). The resulting antigenantibody complexes were visualized using a diaminobenzidine-hydrochloride substrate solution (DAB, No. K3468; DakoCytomation). The cell nuclei were counterstained using Mayer's hematoxylin. Concomitantly, tissue samples with appropriate positive immunostaining were used as indicators of the quality of the target retrieval procedure. As internal positive controls P-gp immunoreactivity in human kidney tissue and BCRP immunoreactivity in human placenta tissue were used. The immunohistochemical (IHC) results were independently evaluated by two pathologists using a Leica DM2500 microscope (Leica Microsystems, Wetzlar, Germany). The P-gp and BCRP immunoreactivities were assessed using a semiquantitative method based on the percentage of stained cells-membranes (no immunoreactivity $0=$ $0 \%, 1 \leq 10 \%, 2=11-50 \%$ and $3 \geq 50 \%$ ). Samples with scores of 2 and 3 were considered positive, i.e., having a high immunoreactivity $[30,31]$.

\subsection{Cells and culture conditions}

The ATC cell line $8505 \mathrm{C}$ was a generous gift from Prof. Alfredo Fusco from the Institute of Endocrinology and Experimental Oncology, National Centre of Research, Naples, Italy. The Rho- subline was derived from $8505 \mathrm{C}$ by sorting a small sub-population (up to $1.6 \%$ ) of $8505 \mathrm{C}$ cells exhibiting a low Rhodamine 123 (Rho 123) accumulation. The ATC cell line SW1736 was obtained from Cell Lines Service GmbH (Eppelheim, Germany). The parental 8505C cell line $8505 \mathrm{C}$ and its derivative Rho- were cultured in DMEM supplemented with $10 \%$ heat-inactivated fetal bovine serum (FBS), $2 \mathrm{mM} \mathrm{L-glutamine,} 4.5 \mathrm{~g} / 1$ glucose, 10,000 U/ $\mathrm{ml}$ penicillin and $10 \mathrm{mg} / \mathrm{ml}$ streptomycin at $37^{\circ} \mathrm{C}$ in a humidified atmosphere containing 5\% $\mathrm{CO}_{2}$. SW1736 cells were maintained in RPMI-1640 medium containing $10 \%$ heatinactivated FBS, $2 \mathrm{mM}$ L-glutamine, 10,000 U/ml penicillin, $10 \mathrm{mg} / \mathrm{ml}$ streptomycin and $25 \mathrm{mg} / \mathrm{ml}$ amphotericin B solution at $37{ }^{\circ} \mathrm{C}$ in a humidified atmosphere containing $5 \% \mathrm{CO}_{2}$. All cell lines were sub-cultured at $72 \mathrm{~h}$ intervals using $0.25 \%$ trypsin/EDTA and seeded in fresh media at the following densities: $8000 \mathrm{cells} / \mathrm{cm}^{2}$ for $8505 \mathrm{C}$ and $16,000 \mathrm{cells} / \mathrm{cm}^{2}$ for Rho- and SW1736.

\subsection{Drugs}

PTX was purchased from Sigma-Aldrich Chemie Gmbh (Taufkirchen, Germany) and AZD2014 was kindly provided by Selleckchem (Houston, TX, USA). PTX was diluted in absolute ethanol after which $1 \mathrm{mM}$ aliquots were stored at $-80^{\circ} \mathrm{C}$. AZD2014 was diluted in DMSO (dimethyl sulfoxide) after which $10 \mathrm{mM}$ aliquots were stored at $-20^{\circ} \mathrm{C}$. Before use, all drugs were freshly diluted in sterile water.

\subsection{MTT cell growth assay}

The MTT cell growth assay is based on the reduction of 3-(4, 5-dimethyl-2-thizolyl)-2,5-diphenyl-2H-tetrazolium bromide into formazan dye by active mitochondria in living cells. $8505 \mathrm{C}$ and Rho- cells grown in $25 \mathrm{~cm}^{2}$ tissue flasks were trypsinized, seeded into flat-bottomed 96-well tissue culture plates $(2000 \mathrm{cells} / \mathrm{well})$ and incubated overnight in $100 \mu \mathrm{l}$ appropriate medium. After $24 \mathrm{~h}$, the cells were treated with either AZD2014 (5, 10, 25, 50 and $100 \mathrm{nM})$ or PTX $(50,100$, 250, 500 and $1000 \mathrm{nM}$ ) and incubated for $72 \mathrm{~h}$ in complete medium. The combined effect of AZD2014 and PTX after $72 \mathrm{~h}$ was studied using different concentrations of AZD2014 (50, 100 and $150 \mathrm{nM})$ combined with different concentrations of PTX $(50,100,250,500$ and $1000 \mathrm{nM})$. After incubation, $100 \mu \mathrm{l}$ MTT solution $(1 \mathrm{mg} / \mathrm{ml})$ was added to each well after which the plates were incubated at $37^{\circ} \mathrm{C}$ for $4 \mathrm{~h}$. Following MTT removal, the formazan products were dissolved in $200 \mu \mathrm{LMSO}$ and absorbance was measured at $540 \mathrm{~nm}$ using an automated microplate reader (LKB 5060-006 Micro Plate Reader, LKB, Vienna, Austria). Half-maximal inhibitory concentration (IC50) values were defined as the concentration of the drug that inhibited cell growth by $50 \%$ and was calculated by non-linear regression analysis using GraphPad Prism 6 software. The procedure for SW1736 cells is described in the Online Resource, Material and Methods section.

\subsection{Median effect analysis}

The interaction between AZD2014 and PTX was analyzed using CalcuSyn software (Biosoft, Cambridge, United Kingdom) based on the combination index (CI) method and the multiple drug effect equation [32]. This analysis requires that at least 3 data points for each single drug are available in each experiment. The non-constant ratio combination design was chosen to assess the effect of both drugs in combination. The results obtained are presented as fraction-affected CI graphs. CI values $<1$ indicate additive effects or synergism, i.e., the smaller the value the higher the degree of synergy. A CI value of 1 indicates an additive effect and CI values $>1$ indicate antagonistic effects.

\subsection{Rho 123 accumulation assay}

Accumulation of the P-gp substrate Rho 123 was analyzed by flow cytometry. The analyses were carried out on $1 \times 10^{7}$ untreated $8505 \mathrm{C}$ cells cultured in $75 \mathrm{~cm}^{2}$ flasks, trypsinized, 
counted and re-suspended in $5 \mathrm{ml}$ falcon tubes in a Rho 123containing medium $(5 \mu \mathrm{M})$. Next, the cells were incubated in the dark at $37{ }^{\circ} \mathrm{C}$ in $5 \% \mathrm{CO}_{2}$ for $30 \mathrm{~min}$, after which the cells were pelleted by centrifugation, washed in ice-cold phosphate buffered saline (PBS) and placed in ice-cold PBS. The samples were kept on ice in the dark until analysis by flow cytometry (see below). Rho 123 fluorescence was detected using a $530 / 30 \mathrm{~nm}$ band pass filter after which 160,000 cells with the lowest Rho 123 accumulation were sorted in a sterile falcon tube with FBS ( $\sim 1.6 \%$ of each sample). The sorted cells were transferred to culture medium and after one month in culture, the resulting Rho- cells were characterized with respect to Rho 123 accumulation and P-gp/BCRP expression.

\subsection{Flow cytometry}

Rho 123 accumulation by ATC cells (see above) was assessed using flow cytometry (BD FACSAria ${ }^{\mathrm{TM}}$ III, BD Biosciences, San Diego, USA). A minimum of 20,000 events was assayed for each sample (the gate excluded cell debris and dead cells) and the obtained results were analyzed using FlowJo 7.6 software (FlowJo, LCC, BD Biosciences). Flow cytometry was also used to measure P-gp and BCRP expression levels in ATC cells. To this end, cells $\left(2 \times 10^{5}\right)$ were collected by trypsinization, washed in ice-cold PBS and directly immunostained using FITC-conjugated anti-P-gp and anti-BCRP antibodies according to the manufacturer's protocol (BD Biosciences, United Kingdom). An isotype control IgG2bk (Abcam, Cambridge, United Kingdom) was used for each experimental sample to determine the level of background fluorescence of negative cells. The mean fluorescence intensity was determined for positively stained cells. The samples (for all analyses) were washed in ice-cold PBS and kept on ice in the dark until flow cytometric analysis (BD FACSCalibur ${ }^{\mathrm{TM}}$, Becton Dickinson, Oxford, United Kingdom). Also, Rho- cells treated for $72 \mathrm{~h}$ with $100 \mathrm{nM}$ AZD2014, 100 nM PTX and their combination were subjected to P-gp and BCRP expression analyses. The fluorescence intensities of Rho 123 and the FITC-conjugated anti-P-gp and anti-BCRP antibodies were assessed using fluorescence channel 1 (FL1-H) at $530 \mathrm{~nm}$. A minimum of 10,000 events was assayed for each sample (the gate excluded cell debris and dead cells) and the obtained results were analyzed using Cell Quest Pro software (Becton Dickinson, Oxford, United Kingdom).

\subsection{CFSE proliferation assay}

The carboxyfluorescein succinimidyl ester (CFSE) dye binds covalently to free amines on the surface of and inside cells with a minimal effect on their proliferative capacity. This dye enables the monitoring of cells over a period of 15 divisions [33]. The fluorescence intensity of CFSE gradually declines during cell divisions, thereby enabling the assessment of cell proliferation rates in treated versus untreated cells. For CFSE labeling, $8505 \mathrm{C}$ and Rho- cells were incubated $10 \mathrm{~min}$ in $0.1 \% \mathrm{FBS} / \mathrm{PBS}$ solution containing $10 \mu \mathrm{M} \mathrm{CFSE}$ at $37{ }^{\circ} \mathrm{C}$, after which the cells were washed three times with PBS. Next the CFSE treated cells $\left(2 \times 10^{5}\right)$ were seeded in 6-well plates, adapted overnight and then treated with AZD2014, PTX and their combination. $8505 \mathrm{C} /$ Rho- cells were treated with $100 \mathrm{nM}$ AZD2014, $30 \mathrm{nM} / 300 \mathrm{nM}$ PTX and corresponding combinations of $100 \mathrm{nM}$ AZD2014 and $30 \mathrm{nM} / 300 \mathrm{nM}$ PTX. The AZD2014 concentration $(100 \mathrm{nM})$ was below the IC50 value, while the PTX concentrations $(30 \mathrm{nM} / 300 \mathrm{nM})$ were close to the IC50 values for both cell lines. After $72 \mathrm{~h}$, the cells were trypsinized and washed twice in ice-cold PBS. Finally, the cells were re-suspended in $1 \mathrm{ml}$ PBS and the fuorescence intensities of at least 20,000 cells per sample were measured using the FL2 channel on a CyFlow Space flow cytometer (Partec, Münster, Germany) and analyzed using Summit analysis software (Dako Colorado Inc., USA).

\subsection{Cell death assay}

The percentages of apoptotic, necrotic and viable cells were determined using AV-FITC/PI labeling. To this end, 8505C and Rho- cells $\left(2 \times 10^{5}\right)$ were seeded in 6-well plates and allowed to adhere overnight. Next, the cells were subjected to 100 and $300 \mathrm{nM} \mathrm{AZD2014,} 10$ and $30 \mathrm{nM} / 100$ and $300 \mathrm{nM}$ PTX and corresponding combinations of $100 \mathrm{nM}$ AZD2014 with $30 \mathrm{nM} / 300 \mathrm{nM}$ PTX. After $72 \mathrm{~h}$, the cells (both attached and floating) were collected, spun down and re-suspended in $100 \mu \mathrm{l}$ binding buffer containing AV-FITC and PI in a 1:1 (v/ v) ratio. After incubation for $10 \mathrm{~min}$ at room temperature in the dark, an additional $400 \mu$ l binding buffer was added after which AV-FITC/PI staining was analyzed within $1 \mathrm{~h}$ by flow cytometry. The fluorescence intensities were measured in the green (FL1) and red (FL2) channels on a CyFlow Space flow cytometer (Partec, Münster, Germany), respectively. In each sample 20,000 cells were recorded, and the percentages of viable $(\mathrm{AV}-/ \mathrm{PI}-)$, early apoptotic $(\mathrm{AV}+/ \mathrm{PI}-)$, late apoptotic $(\mathrm{AV}+\mathrm{PI}+)$ and necrotic $(\mathrm{AV}-/ \mathrm{PI}+)$ cells were analyzed using the Summit software tool (Dako Colorado Inc., USA).

\subsection{Autophagosome formation assay}

To visualize the formation of autophagosomes, $8505 \mathrm{C}$ and Rho- cells were labeled with a rabbit anti-LC3 antibody and a secondary Alexa Fluor 488 goat anti-rabbit $\operatorname{IgG}(\mathrm{H}+\mathrm{L})$ antibody. To this end, the cells were incubated overnight in 4-chamber slides and treated with $100 \mathrm{nM}$ AZD2014, $10 \mathrm{nM}$ PTX and their combination for $24 \mathrm{~h}$. Next, the cells were washed in PBS, fixed in 4\% paraformaldehyde and blocked for $60 \mathrm{~min}$ with $2 \%$ bovine serum albumin (Serva, Heidelberg, Germany) in PBS $/ 0.3 \%$ Triton X-100 (Merck KGaA, 
Darmstadt, Germany). Next, the rabbit anti-LC3 antibody was applied at a 1:1000 dilution in PBS/0.3\% Triton X-100 after which the cells were incubated overnight at $4{ }^{\circ} \mathrm{C}$. After washing with PBS, the secondary Alexa Fluor 488 goat anti-rabbit $\operatorname{IgG}(\mathrm{H}+\mathrm{L})$ antibody was applied at a 1:1000 dilution in PBS/ $0.3 \%$ Triton X-100 for $120 \mathrm{~min}$ at room temperature. Subsequently, the nuclei were counterstained with Hoechst 33,342 for $15 \mathrm{~min}$ at room temperature and the cells were mounted in Mowiol (Sigma-Aldrich Chemie GmbH). Finally, the cells were visualized under a Zeiss Axiovert inverted fluorescence microscope (Carl Zeiss Foundation, Oberkochen, Germany) equipped with AxioVision4.8 software. The fluorescence intensity of the captured images was quantified using ImageJ software (U.S. National Institutes of Health, Bethesda, MD, USA).

\subsection{Scratch wound healing assay}

The migratory potential of $8505 \mathrm{C}$ and Rho- cells was assessed using a scratch wound healing assay. To this end, the cells were seeded in 24-well plates and grown for $24 \mathrm{~h}$. Upon reaching confluence, uniform wounds were scratched into the monolayers in each well using a sterile $200 \mu \mathrm{l}$ micropipette tip. Next, the media were replaced and the cells were treated with $100 \mathrm{nM}$ AZD2014, $10 \mathrm{nM}$ PTX and their combination. The subsequent wound closure was monitored by imaging at a $2 \times$ magnification on a Leica microscope (Leica Microsystems $\mathrm{GmbH}$, Wetzlar, Germany) $0 \mathrm{~h}$ and $24 \mathrm{~h}$ after wounding. To measure the degree of closure of the wounded areas, the captured images were analyzed using ImageJ software. Independent experiments were performed in at least triplicate. The procedure for SW1736 cells is described in the Online Resource, Material and Methods section.

\subsection{Gelatin degradation assay}

8505C and Rho- cells were plated on glass coverslips coated with AlexaFluor488-labeled gelatin in 6-well plates (Gelatin from Pig Skin, Oregon Green ${ }^{\circledR} 488$ Conjugate, Life Technologies, USA). Next, the cells were treated with $100 \mathrm{nM}$ AZD2014, $10 \mathrm{nM}$ PTX and their combination. Controls without treatment were included. After $24 \mathrm{~h}$ the cells were fixed with $4 \%$ paraformaldehyde and co-stained with Hoechst 33,342 (Sigma-Aldrich Chemie Gmbh, Germany) and ActinRed 555 (Life Technologies, USA). The cells and the degradation areas were subsequently analyzed at $20 \times$ magnification under a Zeiss Axiovert inverted fluorescence microscope (Carl Zeiss Foundation, Germany). The volumes of the dark areas caused by gelatin degradation were measured using Image J software and normalized to the volumes of the cells. At least 100 cells were analyzed per experiment. The procedure for SW1736 cells is described in the Online Resource, Material and Methods section.

\subsection{Invasion assays}

To evaluate the effect of AZD2014 and PTX on the inhibition of $8505 \mathrm{C}$ and Rho- cell invasion, Transwell inserts (pore size $8 \mu \mathrm{m}$; diameter, $6.4 \mathrm{~mm}$; BD Biosciences Discovery Labware) were used. The cells were seeded in serum-free medium in the upper chambers that were covered with a layer of Matrigel $(500 \mathrm{~g} / \mathrm{ml})$, and treated for $24 \mathrm{~h}$ with $100 \mathrm{nM}$ AZD2014, 10 nM PTX and their combination. Controls without treatment were included. The lower chambers were filled with RPMI-1640 medium containing 10\% fetal bovine serum as chemoattractant. As a control, spontaneous cell invasion without $10 \%$ FBS was assessed. After incubation, the cells that migrated through the membranes were fixed in $4 \%$ paraformaldehyde/PBS, stained with Hoechst 33,342 and counted under a Zeiss Axiovert inverted fluorescence microscope at $10 \times$ magnification. The average number of cells in 30 independent fields per membrane was analyzed using ImageJ software. The results are presented as percentages of cells that invaded through the Matrigel-coated membrane compared to the untreated controls. The procedure for SW1736 cells is described in the Online Resource, Material and Methods section.

\subsection{Spheroid formation assay}

At $\sim 80 \%$ confluence in DMEM/10\% FBS medium, monolayer $8505 \mathrm{C}$ and Rho-cells were dissociated with trypsin-EDTA into single cell suspensions. Next, the cells were seeded in triplicate at multiple densities (ranging from 500 to 10,000 cells) to determine the optimal plating densities in lowattachment 96-well plates (SCIVAX Life Sciences/ SCIVAX USA). After 14 days in culture, spheroid colonies were quantified using inverted phase contrast microscopy (Zeiss Axiovert 40c equipped with a CCD camera; Carl Zeiss Microscopy, Berlin, Germany).

\subsection{In vivo studies}

NSG (NOD scid gamma) and SCID (Severe Combined Immunodeficiency) mice were purchased from the Jackson Laboratory (Bar Harbor, ME, USA). The present study was approved by the Institutional Animal Care and Use Committee of the Faculty of Medicine of the University of Thessaly IACUC and the local Directorate General for Regional Rural Economy and Veterinary (Licence No 5542/ 228006; 30/11/2016). All mice were kept under pathogen-free conditions in the animal facility in a controlled environment (12 h dark/light cycle), fed with standard laboratory chow and given autoclaved water ad libitum. Seven week old NSG and 8-10 week-old SCID female mice were used in this study. 


\subsubsection{NSG mouse models}

The in vivo tumorigenic capacity of $8505 \mathrm{C}$ and Rho- cells was examined in NSG mice using a limited dilution inoculation approach. To this end, 10,000 and 100,000 cells of each cell line were subcutaneously (s.c.) injected into the left and right axillae of the rear flanks after which the mice were monitored three times a week for tumor growth. The tumor sizes were measured using a caliper and the tumor volumes were calculated using the formula $\mathrm{V}\left(\mathrm{mm}^{3}\right)=\mathrm{a} \times \mathrm{b}^{2} / 2$, where $\mathrm{V}\left(\mathrm{mm}^{3}\right)$ is the tumor volume in $\mathrm{mm}^{3}, \mathrm{a}$ - the length of the tumor and $\mathrm{b}$ the width of the tumor. The mice were euthanized when the tumor sizes reached $1500 \mathrm{~mm}^{3}$. Upon euthanasia, the tumors were harvested and manually dissected into tissue fragments by mincing and enzymatic digestion with collagenase, hyaluronidase and DNAse to generate single cell suspensions for flow cytometric analyses. To this end, the cells suspensions were fixed in $4 \%$ paraformaldehyde for $15 \mathrm{~min}$ and kept on ice in the dark until analysis on a FACScalibur machine (Becton Dickinson, Oxford, United Kingdom). The analyses were performed as described above for cell lines.

\subsubsection{SCID mouse models}

SCID mice were used to determine the effectiveness of AZD2014 and PTX (alone and in combination) against tumor growth. For PTX the injectable form administered to patients was kindly donated by the Clinics of Oncology of the University General Hospital of Larissa, Greece. PTX was further diluted in $0.9 \% \mathrm{NaCl}$ for subsequent animal administrations. AZD2014 was dissolved in DMSO and subsequently diluted in $0.5 \%$ Tween $80.1 \times 10^{6} 8505$ and Rho- cells were subcutaneously injected into the right and left axillae of the rear flanks, after which the mice were weighed (mean body weight $22 \mathrm{~g}$ ) and randomly divided into 4 groups for each cell line: a control group $(n=5)$ that received $100 \mu \mathrm{l} 0.9 \% \mathrm{NaCl}$ and $200 \mu \mathrm{l}$ DMSO in $0.5 \%$ Tween 80 via intraperitoneal (i.p.) injections, a PTX group $(n=5)$ that received two i.p. injections $(100 \mu \mathrm{l}$ PTX $5 \mathrm{mg} / \mathrm{kg}$ and $200 \mu \mathrm{l}$ DMSO in $0.5 \%$ Tween $80)$, an AZD2014 group $(n=5)$ that received two i.p. injections $(200 \mu \mathrm{l} \mathrm{AZD2014} 2.5 \mathrm{mg} / \mathrm{kg}$ and $100 \mu \mathrm{l} 0.9 \% \mathrm{NaCl})$ and a combination group $(n=5)$ that received two i.p. injections $(100 \mu \mathrm{l}$ of PTX $5 \mathrm{mg} / \mathrm{kg}$ and $200 \mu \mathrm{l}$ of AZD2014 $2.5 \mathrm{mg} / \mathrm{kg}$ ). The first course of the drugs was applied when tumors generated by both cell lines reached volumes of approximately $100 \mathrm{~mm}^{3}$. Administration schedule was Q7D1 (once/week). The tumors were measured with a caliper and tumor volumes were again calculated using the formula $\mathrm{V}$ $\left(\mathrm{mm}^{3}\right)=\mathrm{a} \times \mathrm{b}^{2} / 2$ (see above). The experiments were terminated when the tumor sizes reached a volume of $1500 \mathrm{~mm}^{3}$. Weight loss and dietary, behavioral and neurological changes were monitored and recorded as markers of drug toxicity. In addition to tumor volumes, the \% DT/DC parameter was calculated, where DT $=\mathrm{T}-\mathrm{Do}$ and $\mathrm{DC}=\mathrm{C}-\mathrm{Do}$ (Do is average tumor volume at the beginning of the treatment; $\mathrm{T}$ and $\mathrm{C}$ are the volumes of the treated and untreated tumors, respectively, at a specified day). The optimal DT/DC value was used as a measure of drug activity [34].

All animals were treated according to the guidelines of the EU and Greek authorities (2010/63/EU directive and Greek PD 56/2013, respectively) governing the use and handling of experimental animals.

\subsection{Statistical analyses}

The CFSE staining, anti-LC3 staining, invasion and tumor growth data were analyzed by Student t-test. Since the gel degradation data were not normally distributed, the Wilcoxon matched-pairs signed rank test was carried out. Two-way ANOVA Dunnett's multiple comparisons test was employed to analyze the cell death induction data. Differences were considered statistically significant when $p \leq 0.05$. Survival data were analyzed using the Kaplan-Meier product-limit method. The significance of differences between low-expressing and high-expressing pairs of survival curves was assessed using the Mantel-Cox log rank test, while overall survival rates were calculated from the first day after surgery to the last follow-up or death of the patient. Cox proportional hazards regression for survival data, hazard ratios (HR) and its corresponding 95\% confidence intervals (95\% CI) were employed for assessing the impact of factors on overall survival. Differences were considered statistically significant when $p \leq 0.05$.

\section{Results}

\subsection{P-gp and BCRP expression in ATC patient samples}

P-gp and BCRP protein expression in 12 primary ATC samples was assessed by immunohistochemistry. By doing so, we observed overexpression of P-gp in $66.7 \%$ of the samples and increased expression of BCRP in $33.3 \%$ of the samples (Fig. 1a-c). Next, Kaplan-Meier survival curves were generated to evaluate the effects of P-gp and BCRP expression on patient survival. We found that the median survival time was 180 days for patients with a low P-gp expression and 69 days for patients with a high $\mathrm{P}$-gp expression (hazard ratio 0.51 , 95\% CI: 0.16 to $1.59, p=0.0662$; Fig. $1 \mathrm{~d}$ ) implying a tendency towards a worse prognosis for ATC patients with a high Pgp expression. No differences were observed between the survival curves of patients with low and high BCRP expression levels (hazard ratio $1.97,95 \% \mathrm{CI}: 0.63$ to $6.16, p=0.5064$ ). In both cases, the confidence intervals were wide (for P-gp and BCRP expression) and affected by the small patient cohort. The hazard ratios were not significantly different. 

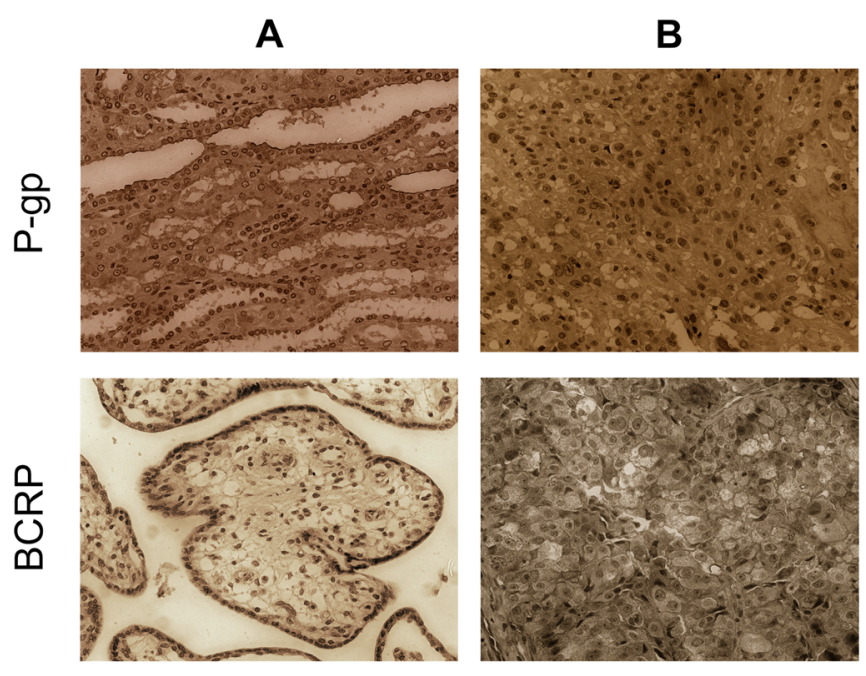

Fig. 1 Immunohistochemical P-gp and BCRP analyses in primary tissue samples. Representative examples of (a) positive P-gp kidney and BCRP placenta controls, (b) low P-gp and low BCRP expressing ATC tissues

\subsection{Isolation of drug resistant Rho- cells}

8505C cells were employed to isolate drug resistant ATC cells that may serve as a model system mimicking the patients' phenotype. A new subline was generated by sorting a small sub-population (up to $1.6 \%$ ) of $8505 \mathrm{C}$ cells exhibiting a low Rho 123 accumulating capacity (Fig. 2a). The sorted cells were placed in culture and after one month the cells, named Rho-, were characterized for P-gp and BCRP expression and Rho123 accumulation. We found that the Rho- cells exhibited an increased expression of the P-gp and BCRP transport pumps and a decreased accumulation of Rho123 compared to the parental $8505 \mathrm{C}$ cells (Fig. 2b).

Next, we evaluated the effect of PTX and AZD2014 on 8505C and Rho- cell growth using a MTT assay (Fig. 2c). The respective cells were treated with 50-1000 nM PTX and 5-100 nM AZD2014 for $72 \mathrm{~h}$ in complete medium. We found that the Rho- cells were more resistant to PTX than the $8505 \mathrm{C}$ cells (IC50 $=202 \mathrm{nM}$ versus $28 \mathrm{nM}$, respectively), while the $8505 \mathrm{C}$ cells were found to be more resistant to AZD2014 $(\mathrm{IC} 50=417 \mathrm{nM})$ than the Rho- cells $(\mathrm{IC} 50=254 \mathrm{nM})$. In addition, we treated the Rho- cells with 100 nM AZD2014 and $100 \mathrm{nM}$ PTX (half the concentrations of their respective IC50s) to assess whether these compounds might affect P-gp expression. Through flow cytometric analyses we found that neither AZD2014 nor PTX interfered with P-gp expression after $72 \mathrm{~h}$ treatment. A similar result was obtained with their combination (Fig. 2d).

\subsection{Rho- cells exhibit an increased tumorigenicity}

To test the tumorigenic potential of $8505 \mathrm{C}$ and Rho- cells, we carried out both in vitro and in vivo experiments. For the
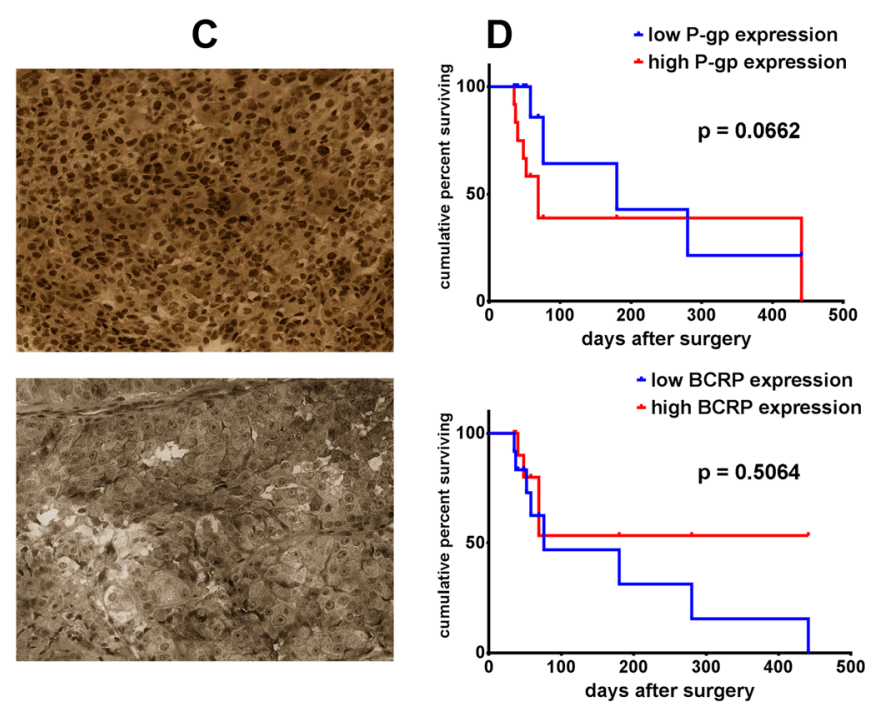

and (c) high P-gp and BCRP expressing ATC tissues (10× objective). d Kaplan-Meier overall survival analyses

in vitro spheroid formation assay, both cell lines were seeded at densities of 5000 and 10,000 cells per well in 96-well plates. By doing so, we found that the Rho- cells generated significantly more spheroids than the $8505 \mathrm{C}$ cells at both densities (Fig. 3a; $p \leq 0.001$ ).

Next, NSG mice were used to test the in vivo tumorigenic potential of $8505 \mathrm{C}$ and Rho- cells. After inoculation of 10,000 cells per cell line, we observed significant differences in tumor growth. Rho- cells appeared to be more tumorigenic, producing tumors on the 25 th day and generating tumor sizes that were significantly larger at the 42 nd day than those of the $8505 \mathrm{C}$ cells (Fig. 3b; $p=0.02$ ). The Rho- cells were also more tumorigenic when 100,000 cells were inoculated, i.e., significantly larger tumor sizes were noted at the 42nd and 51st days (Fig. 3b; $p=0.04$ ). To confirm the original nature of the cells, the tumors were recovered after which single cell suspensions were prepared for flow cytometric analysis of P-gp and BCRP expression levels. We found that the cells originating from the Rho- tumors had preserved their in vitro characteristics, i.e., they exhibited higher P-gp and BCRP expression levels than those originating from the $8505 \mathrm{C}$ tumors (Fig. 3c).

\subsection{AZD2014 enhances the sensitivity of 8505C and Rho- cells to PTX}

Next, we set out to evaluate the effect of the combination of AZD2014 and PTX on ATC cell growth inhibition using MTT assays. We found that the application of AZD2014 (50, 100 and $150 \mathrm{nM}$ ) significantly decreased the IC50 values for PTX in both $8505 \mathrm{C}$ and Rho- cells. The effect was more pronounced in Rho- cells, showing a more than two-fold decrease in IC50 for PTX when combined with 100 and 150 nM AZD2014 (Fig. 4a). The MTT results were analyzed using a synergism/ 
A

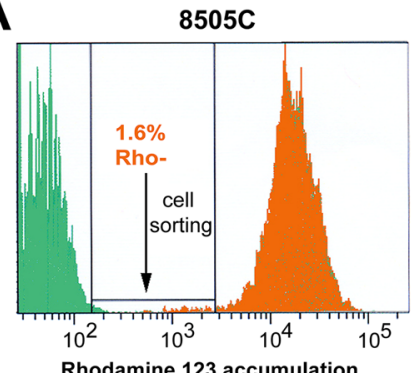

B
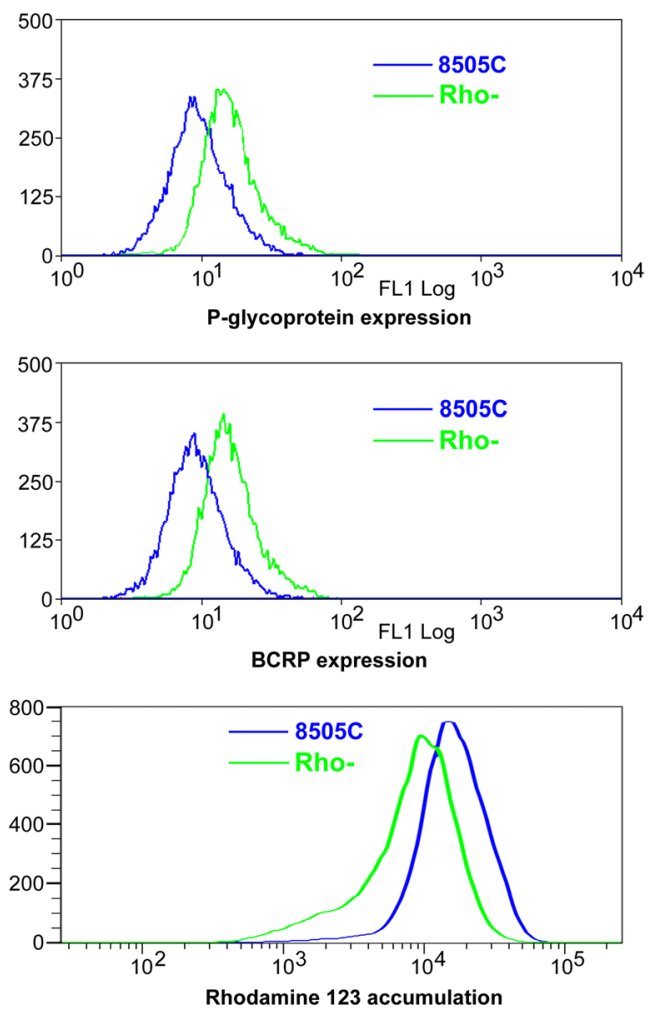

Fig. 2 Isolation of $8505 \mathrm{C}$ cells exhibiting a low Rho 123 accumulating capacity. a $8505 \mathrm{C}$ cells (arrow) exhibiting the lowest Rho 123 accumulation (orange histogram) sorted and cultured as Rho- cells; green histogram represents unstained $8505 \mathrm{C}$ cells under the same experimental conditions. b P-gp expression, BCRP expression and Rho 123 accumulation in $8505 \mathrm{C}$ and Rho- cells. Two independent

antagonism CalcuSyn software tool. We found that all treatment combinations showed synergistic effects $(\mathrm{CI}<1)$ in the Rho- cells (Fig. 4a). A similar synergistic effect of AZD2014 and PTX was previously observed in another ATC cell line, SW1736 [10]. It was found that the IC50 value for PTX in SW1736 cells was $0.093 \mu \mathrm{M}$, while AZD2014 inhibited their growth by $50 \%$ with $0.15 \mu \mathrm{M}$. When AZD2014 was applied in a range below the IC50 $(0.01,0.025$ and $0.05 \mu \mathrm{M})$ a considerable decrease in IC50 was noted for PTX [10].

Subsequently, we analyzed the effect of $100 \mathrm{nM}$ AZD2014 on $8505 \mathrm{C}$ and Rho- cell proliferation using CFSE staining and found that AZD2014 has a tendency to suppress the proliferation of both cell lines (Fig. 4b). PTX was used in concentrations close to, but above, the IC50 $(30 \mathrm{nM}$ for $8505 \mathrm{C}$ and
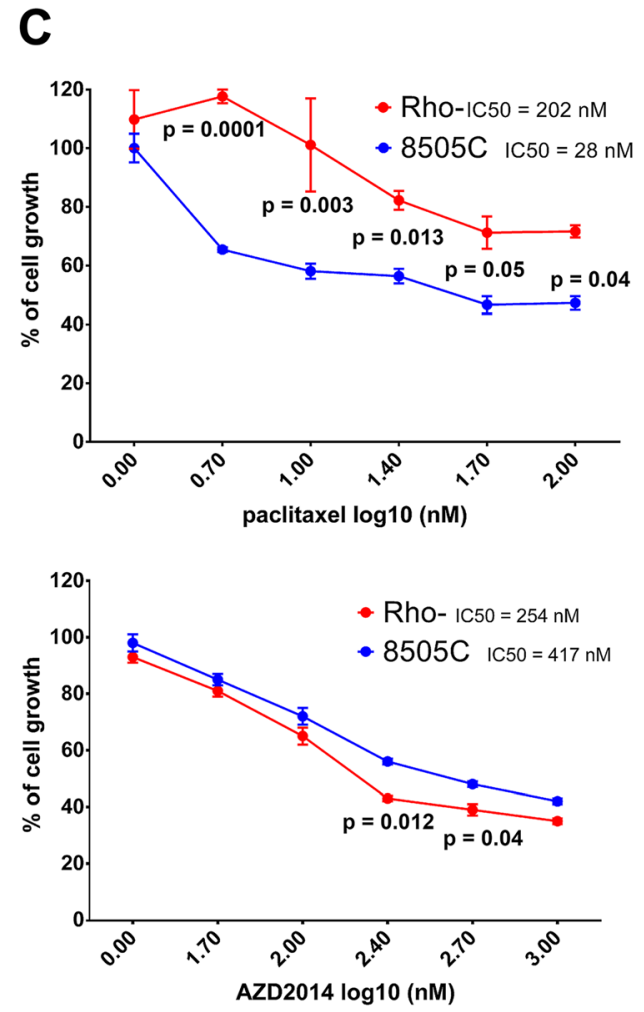

AZD2014 $\log 10$ (nM)

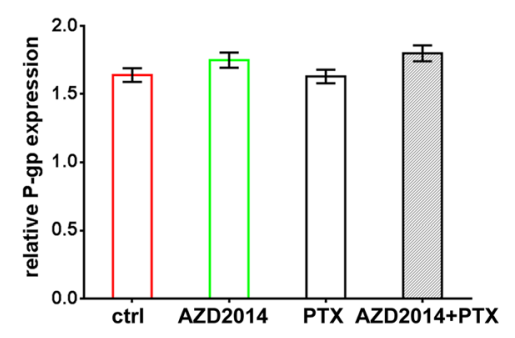

experiments were performed. c AZD2014 and PTX effects on $8505 \mathrm{C}$ and Rho- cell growth. Average values are obtained from five independent experiments $(n=5)$. IC50 values are included next to the graphs. d P-gp expression analysis of Rho- cells exposed to $100 \mathrm{nM}$ AZD2014, $100 \mathrm{nM}$ PTX and their combination for $72 \mathrm{~h}$.

$300 \mathrm{nM}$ for Rho-) and, by doing so, we found that its effects were more pronounced in Rho- cells than in $8505 \mathrm{C}$ cells (Fig. $4 \mathrm{~b})$. Only suppression of cell proliferation induced by the combined application of $100 \mathrm{nM}$ AZD2014 and PTX, in both $8505 \mathrm{C}$ and Rho-, was found to be significantly different from untreated cells (Fig. 4b).

To determine whether cell death induction contributes to the observed synergism between AZD2014 and PTX we employed AV-FITC/PI flow cytometry. We found that the applied concentrations of AZD2014 (100 and $300 \mathrm{nM})$ did not induce cell death in either $8505 \mathrm{C}$ or Rho- cells, whereas PTX showed a significant potential to kill these cells (Fig. 5a). Both concentrations of PTX (10 and $30 \mathrm{nM}$ for $8505 \mathrm{C} / 100$ and $300 \mathrm{nM}$ for Rho-) led to significant increases in the portion 
A

$8505 \mathrm{C}$ 10000 cells

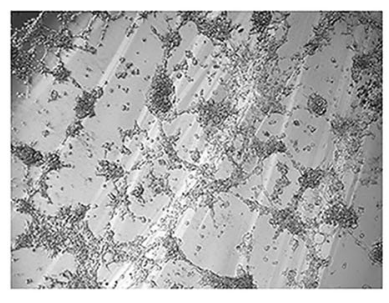

Rho10000 cells

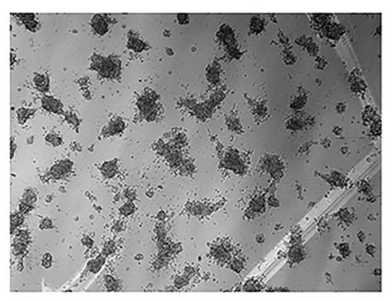

Sphere forming assay

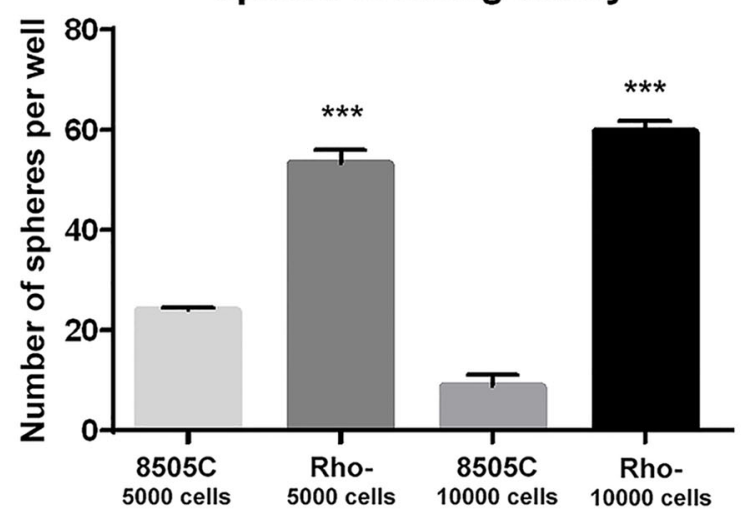

C

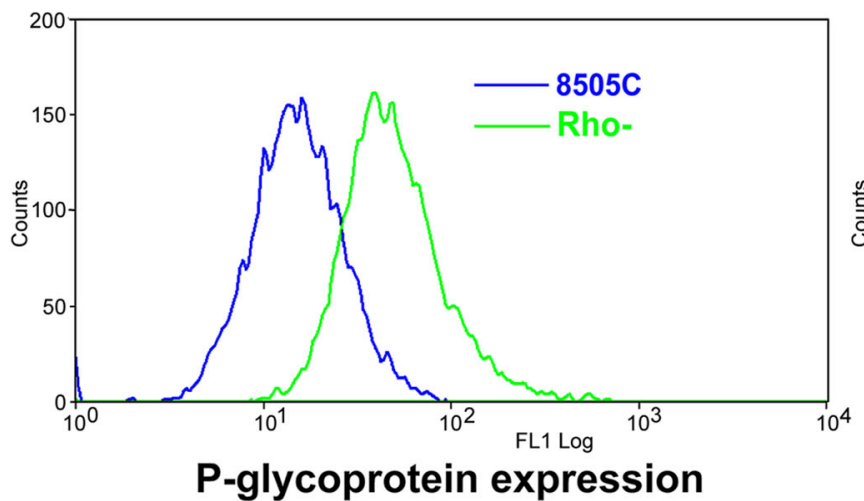

Fig. 3 Tumorigenic potential of ATC cells in vitro and in vivo. a A spheroid forming assay was employed to test the tumorigenic potential of ATC cells in vitro. $8505 \mathrm{C}$ and Rho- cells were seeded at two densities (5000 and 10,000 cells/well) after which significant differences in spheroid formation were found $(* * * p \leq 0.001)$. b 10,000 and 100,000 $8505 \mathrm{C}$ or Rho- cells were injected subcutaneously in the left and right flanks of NSG mice to induce solid tumors. Statistical significance is

of apoptotic and necrotic cells (Fig. 5a). We found, however, that a combination with $100 \mathrm{nM}$ AZD2014 did not improve the effect of PTX. Contrary, we found that AZD2014 significantly diminished the effect of PTX in both cell lines by increasing the portion of viable cells while decreasing the portion of apoptotic and necrotic cells (Fig. 5a; $p \leq 0.001$ ).
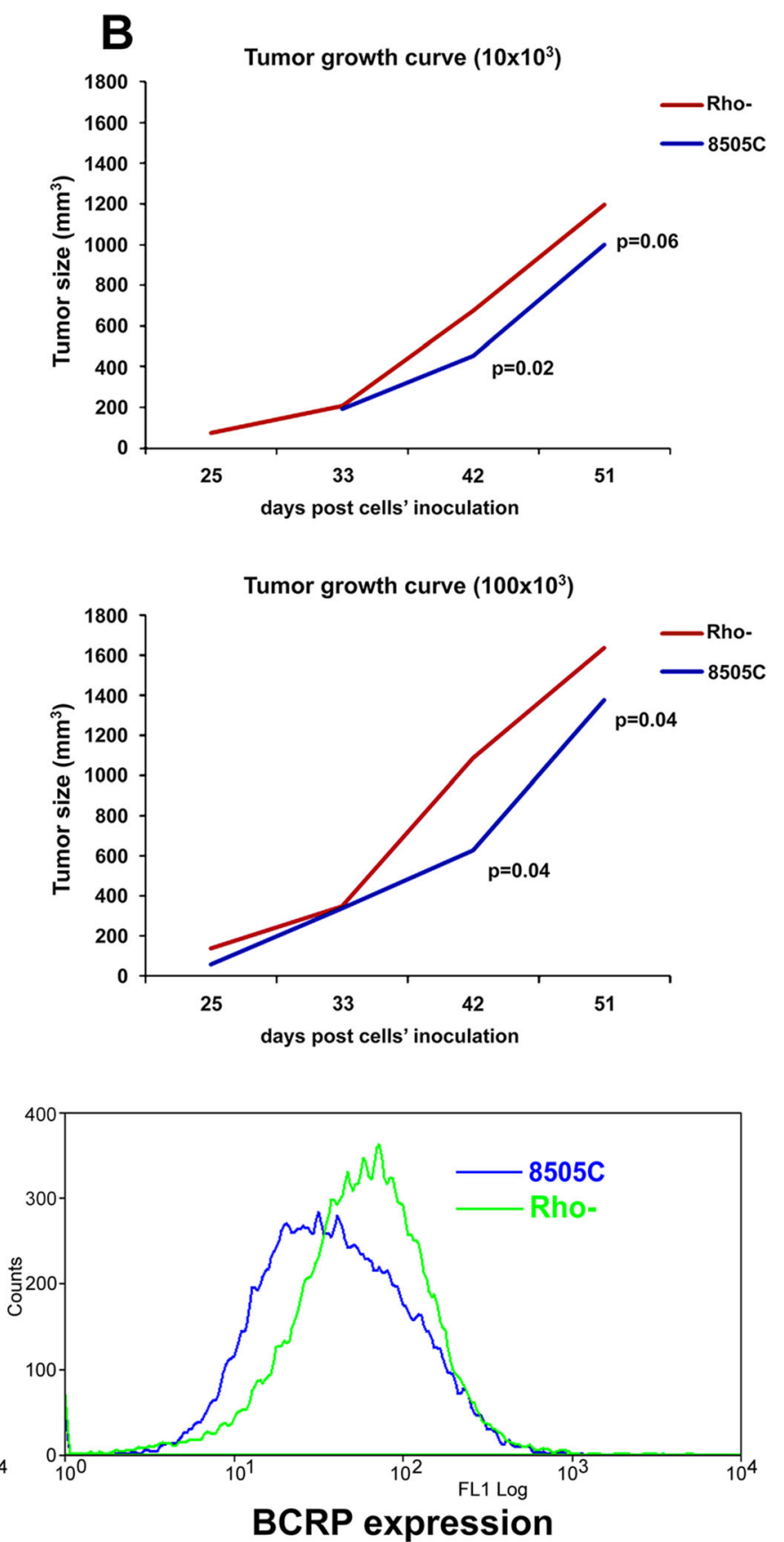

included in the graphs. $\mathbf{c}$ Flow cytometric P-gp and BCRP expression profiles of cell suspensions form $8505 \mathrm{C}$ and Rho- tumors using FITCconjugated anti-P-gp and anti-BCRP antibodies. The P-gp and BCRP expression profiles of $8505 \mathrm{C}$ cells are presented in blue and those of Rho- in green. Two independent experiments were performed (a minimum of 10,000 events was collected for each experimental sample)

Knowing that AZD2014 is an autophagy inducer, we set out to visualize the formation of autophagosomes in $8505 \mathrm{C}$ and Rho- cells after single and combined treatments with 100 nM AZD2014 and 10 nM PTX. We found that both compounds significantly induced autophagosome formation. The presence of autophagy was most prominent after the 


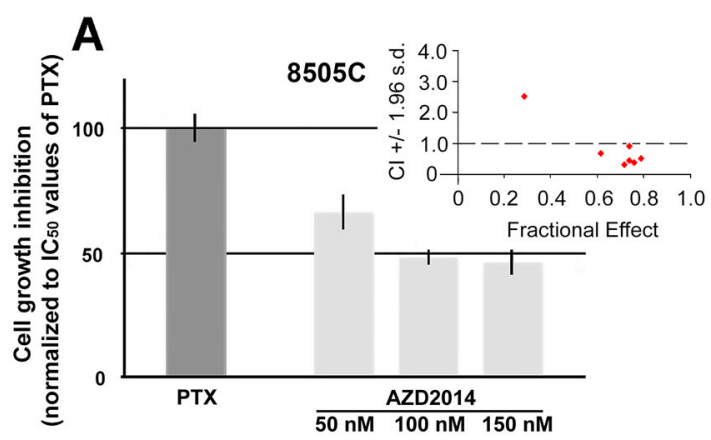

\section{B}

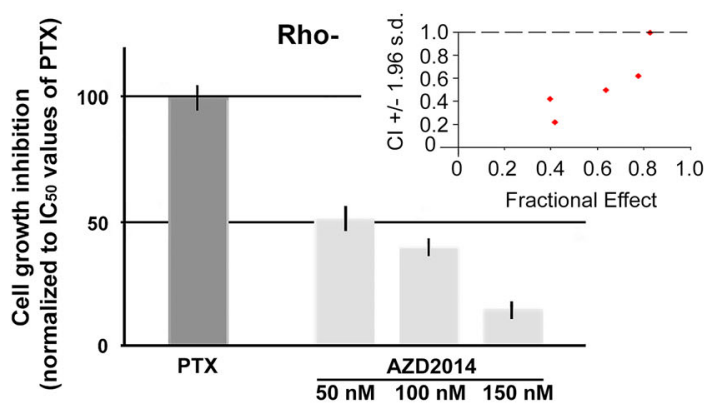

$8505 C$

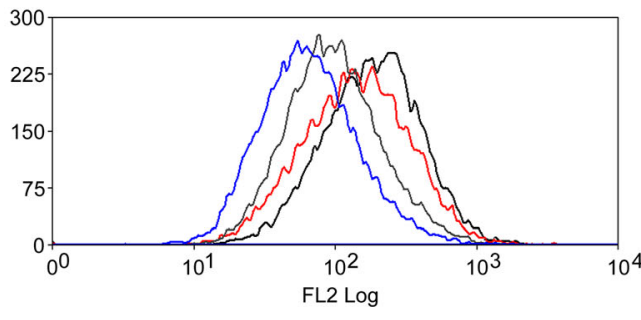

Rho-

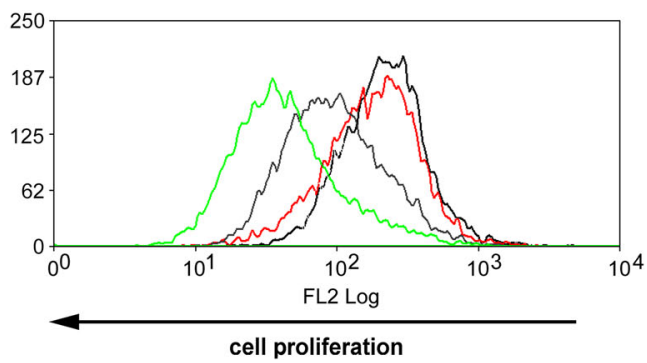

- ctrl

- AZD2014 $100 \mathrm{nM}$ - PTX $30 \mathrm{nM}$

AZD2014 $100 \mathrm{nM}$ + PTX $30 \mathrm{nM}$

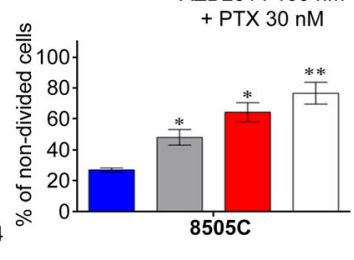

- ctrl

AZD2014 $100 \mathrm{nM}$ - PTX $30 \mathrm{nM}$ AZD2014 $100 \mathrm{nM}$ + PTX $30 \mathrm{nM}$

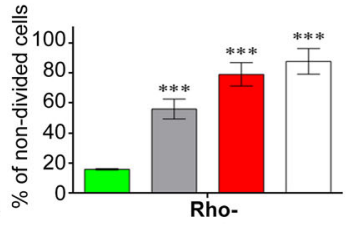

Fig. 4 Anti-proliferative effects of single and combined AZD2014 and PTX treatments. a PTX treatment IC50 values obtained by MTT assay after $72 \mathrm{~h}$ normalized and compared to simultaneous AZD2014 and PTX treatment IC50 values. Average \pm SD values were deduced from four or more independent experiments $(n \geq 4)$. The interactions between AZD2014 and PTX were analyzed using CalcuSyn software. CI values $<1$ indicate a synergistic effect. b $8505 \mathrm{C}$ and Rho- cells treated with

combined treatments. Subsequent quantification of the results revealed a significant increase of anti-LC3 fluorescence intensity when the combined treatment was compared with the single treatments, implicating a possible synergy between AZD2014 and PTX (Fig. 5b).

\subsection{AZD2014-PTX combinations decrease the migratory and invasive capacities of ATC cells}

To evaluate the migratory potential of $8505 \mathrm{C}$ and Rho- cells after single and combined treatments, the cells were seeded in 24-well plates and grown for $24 \mathrm{~h}$. After the subsequent induction of scratch wounds, the respective cells were treated with $10 \mathrm{nM}$ PTX and $100 \mathrm{nM}$ AZD2014. Although we found that the single treatments did not change the migratory properties of either cells, the wound closure rate of $8505 \mathrm{C}$ (Fig. 6a) and Rho- (Fig. 6b) cells was significantly decreased after the combined treatment $(p \leq 0.05)$, suggesting a slower rate of migration. Similar results were obtained with the ATC cell line SW1736 (Online Resource Fig. S1A).

Next, a gelatin degradation assay was performed to test the ability of ATC cells to degrade the extracellular matrix after single and combined treatments with $100 \mathrm{nM}$ AZD2014 and $10 \mathrm{nM}$ PTX. We found that the ability of $8505 \mathrm{C}$ (Fig. 7a) and Rho- (Fig. 7b) cells to degrade gelatin was significantly inhibited after application of the combined treatment $(p \leq$

AZD2014, PTX and their combination for $72 \mathrm{~h}$ and stained with CFSE. The rate of cell proliferation (CFSE fluorescence intensity declination) was determined by flow cytometry on channel FL2 (8505C control - blue line, Rho- control - green line, AZD2014 treatment - grey line, PTX treatment - red line, combined treatment - black line). *p $\leq 0.05, * * p<$ $0.001, * * * p<0.0001$ : statistically significant differences from untreated controls. Two independent experiments were performed $(n=2)$

0.001 and $p \leq 0.01$, respectively). Specifically, we found that the combined treatment caused more than two-fold decreases in degradation areas compared to the respective untreated controls, and was more efficient than the single treatments. SW1736 cells were found to be more sensitive to a single PTX treatment than $8505 \mathrm{C}$ and Rho- cells (Online Resource Fig. S1B). The effect of the combined treatment, however, significantly surpassed the extent of gel degradation observed after PTX treatment alone.

Fig. 5 Cell death and autophagy induction after single and combined AZD2014 and PTX treatments. a Flow cytometric profiles represented as two-dimensional dot-blots: increase in green fluorescence intensity (Annexin V-FITC, FL1) indicates apoptotic cells and increase in red fluorescence intensity (PI, FL2) indicates necrotic cells. Quantifications and statistical analyses are presented in histograms. ${ }^{\$ \$} p \leq 0.001$ : statistically significant difference between PTX and untreated samples. $* * * p \leq$ 0.001: statistically significant difference between AZD2014 and combined treatments. ${ }^{\# \#} p \leq 0.01$ and ${ }^{\# \# \#} p \leq 0.001$ : statistically significant difference between PTX and combined treatments. Three independent experiments were performed $(n=3)$. b Accumulation of cytoplasmic autophagosomes after $24 \mathrm{~h}$ treatment in $8505 \mathrm{C}$ and Rho- cells, visualized by anti-LC3 antibody labeling. Nuclei were counterstained with Hoechst 33,342. Scale bar $=100 \mu \mathrm{m}$. A representative experiment of two independent experiments $(n=2)$ is presented. The quantification and statistical analysis of anti-LC3 fluorescence intensities are presented in histograms. $\$ p \leq 0.05,{ }^{\$} p \leq 0.01$ and ${ }^{\$ \$} p \leq 0.001$ : statistically significant differences between single or combined treatments and untreated samples. $* p \leq 0.05$ : statistically significant difference between AZD2014 and combined treatment. ${ }^{\#} p \leq 0.05$ and ${ }^{\# \#} p \leq 0.01$ : statistically significant differences between PTX and combined treatments 

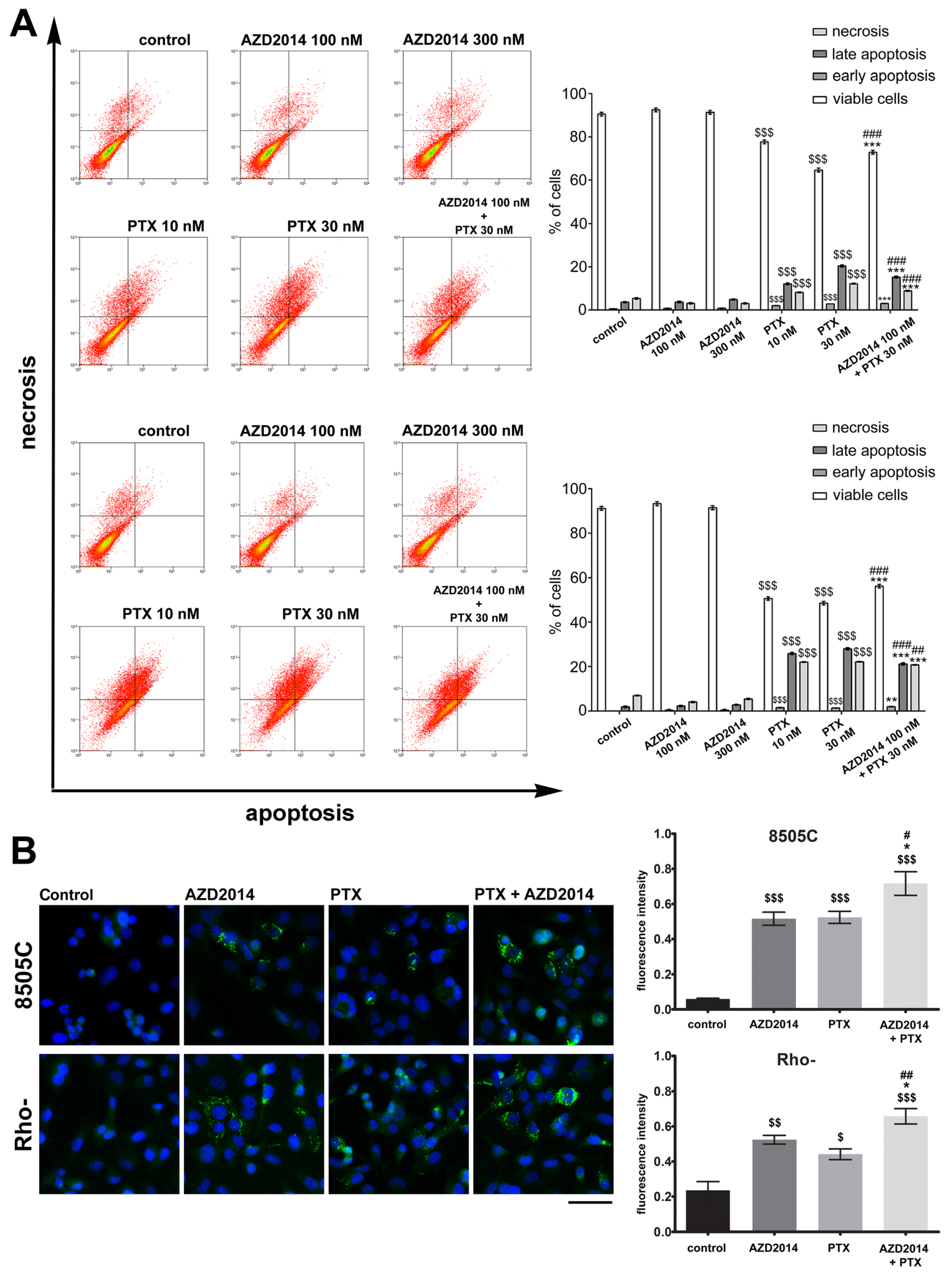
A

to
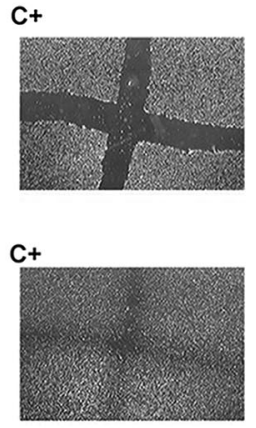

B

to

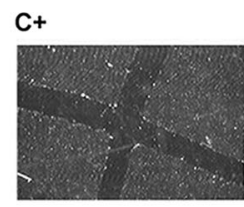

\section{C+}

t24

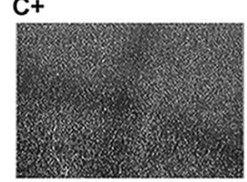

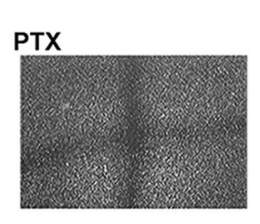
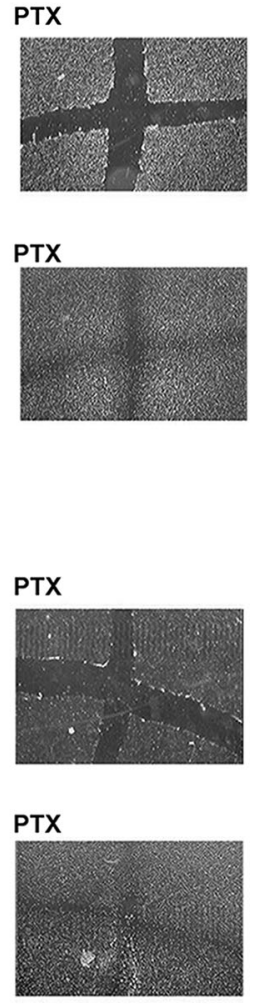
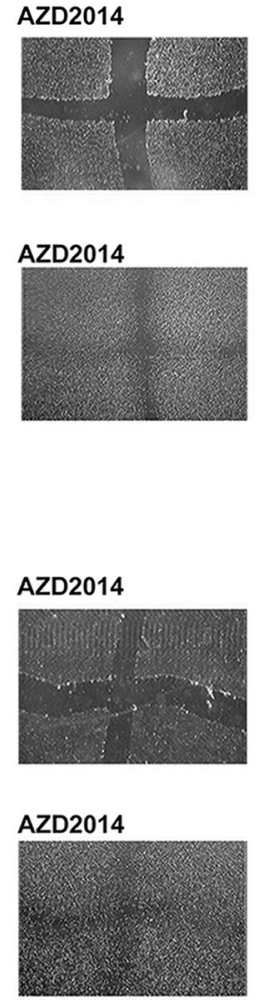

Fig. 6 Inhibition of cell migration after single and combined AZD2014 and PTX treatments. The cells were seeded in 24-well plates and grown for $24 \mathrm{~h}$. After scratch wounding (a) $8505 \mathrm{C}$ and (b) Rho- cells were treated with $10 \mathrm{nM}$ PTX, $100 \mathrm{nM}$ AZD2014 and their combination.

Finally, an invasion assay was performed to test the potential of ATC cells to invade through matrigel after single and combined treatments with $100 \mathrm{nM}$ AZD2014 and $10 \mathrm{nM}$ PTX. We found that $8505 \mathrm{C}$ cell invasion through matrigel was significantly decreased after a single application of AZD2014 ( $p \leq$ 0.05 ), and even more so after a combined treatment with PTX (Fig. 8a; $p \leq 0.001$ ). The combination also significantly suppressed Rho- and SW1736 cell invasion (Fig. 8b, $p \leq 0.001$; Online Resource Fig. S1C, $p \leq 0.001$ ).

\subsection{Effects of AZD2014 and PTX on ATC tumor growth in vivo}

To investigate the efficacy of PTX and AZD2014 (alone and in combination) against ATC tumor growth, $8505 \mathrm{C}$ and Rhoxenografts were generated in SCID mice. The mice were randomly divided into five groups for each cell line: control group without treatment; control group with carriers of drugs; group treated with PTX $(5 \mathrm{mg} / \mathrm{kg}$, once a week); group treated with AZD2014 (2.5 mg/kg, once a week) and group treated with the combination of PTX and AZD2014. We found that the PTX and AZD2014 combination showed a stronger impact on tumor
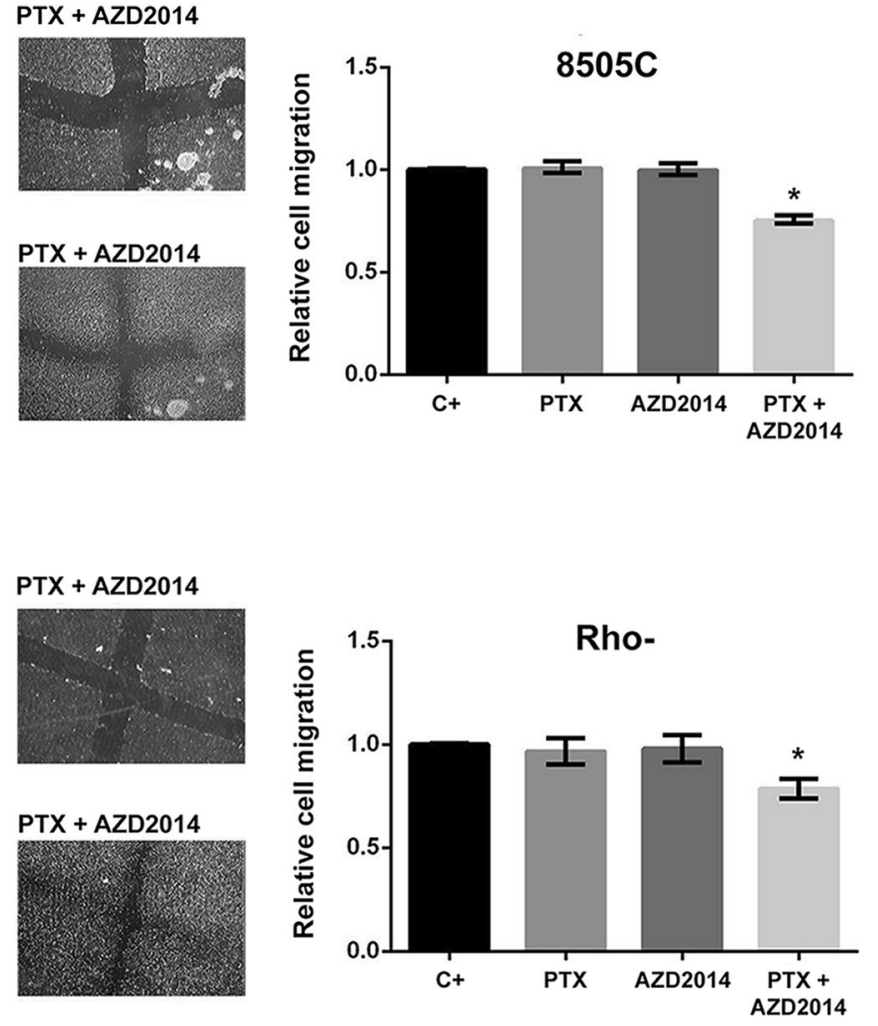

Wound closure was monitored immediately (t0) and $24 \mathrm{~h}$ after wounding (t24). $* p \leq 0.05$ : statistically significant difference between treatments and untreated control. Three independent experiments were performed $(n=3)$

growth suppression in both types of xenografts compared to the control groups as well as to the single treatment groups (Fig. 9a). Specifically, we found that the combination suppressed tumor growth of $8505 \mathrm{C}$ xenografts starting at the 26th day $(p \leq 0.05$ versus controls and single treatments, Fig. $9 \mathrm{a}, \mathrm{b})$, and that it also showed the optimal \%DT/DC value (37\%) up to the 37 th day (\%DT/DC $82 \% p \leq 0.05$ versus controls and AZD2014 and $p=0.09$ versus PTX; Fig. 9a, b). AZD2014 alone showed a good activity with an optimal $\% \mathrm{DT} / \mathrm{DC}$ at day $28(44 \%, p \leq 0.01$ versus controls, Fig. 9a, b), but lost its efficacy soon thereafter (i.e., \%DT/DC was $102 \%$ at day 37, Fig. 9a, b). In contrast, we found that PTX under the administration schedule tested showed a moderate effect against $8505 \mathrm{C}$ tumor growth throughout the experiments (best \%DT/DC at day 26 was $70 \%, p \leq 0.01$ versus controls, Fig. 9a, b). Against the more resistant Rho- cells, all treatments showed a moderate activity, but again the most efficient treatment was the combination of PTX and AZD2014. More specifically, we found that the optimal \%DT/DC of the combination was $43 \%$ on day 26 ( $p \leq 0.05$ versus controls, Fig. $9 \mathrm{a}, \mathrm{b}$ ) and $84 \%$ on day 37 ( $p \leq 0.05$ versus controls), while the corresponding optimal \%DT/DC for AZD2014 was 57\% on day 26 
Fig. 7 Potential of single and combined AZD2014 and PTX treatments to suppress gelatin degradation. Gelatin degradation assays were performed on (a) $8505 \mathrm{C}$ and (b) Rho- cells treated with $10 \mathrm{nM}$ PTX, $100 \mathrm{nM}$ AZD2014 and their combination. $* * p \leq 0.01$ and $* * * p \leq 0.001$ : statistically significant differences between treated cells and untreated controls. Three independent experiments were performed $(n=3)$

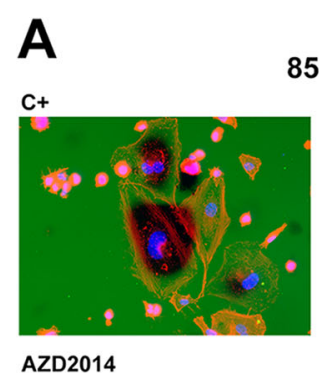

$8505 \mathrm{C}$
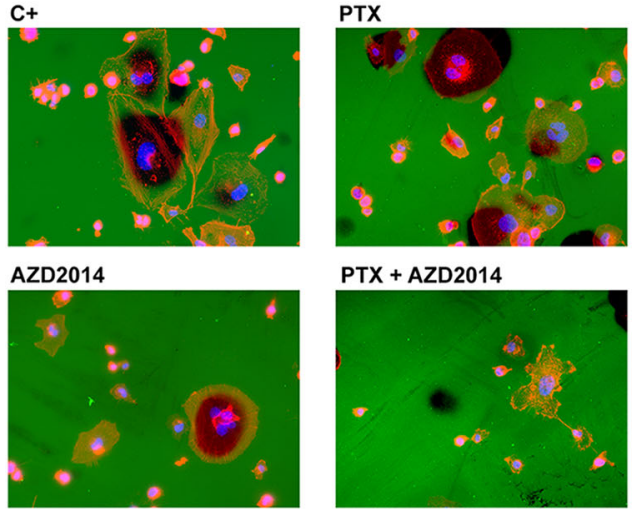

PTX + AZD2014
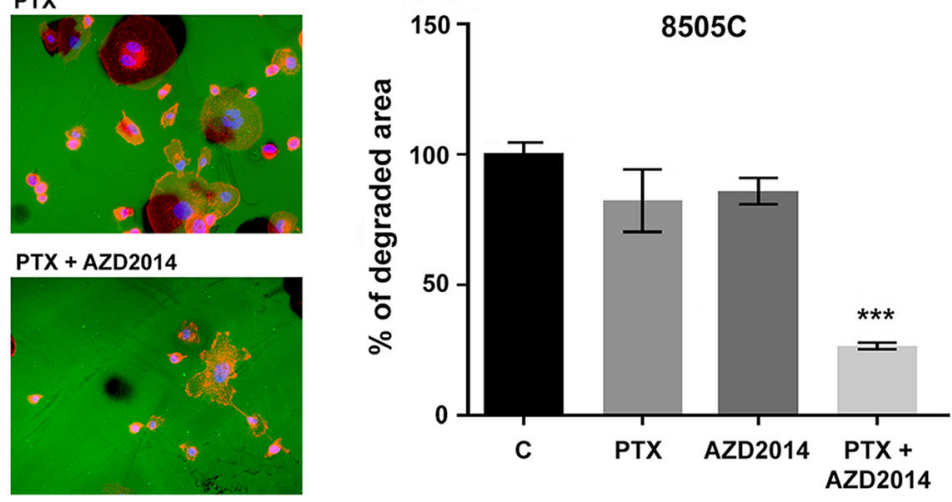

B

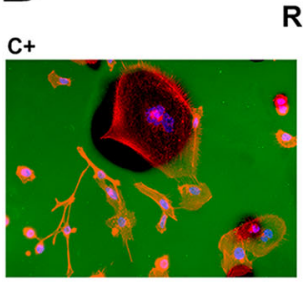

Rho-

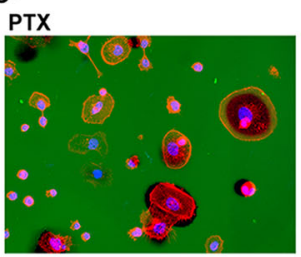

AZD2014

PTX + AZD2014
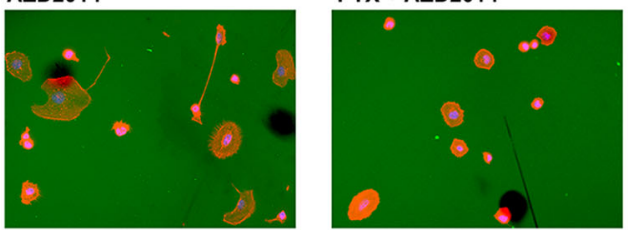

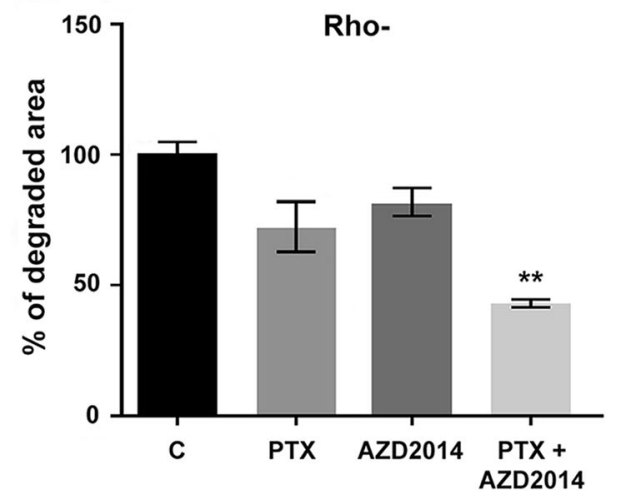

( $p \leq 0.05$ versus controls, Fig. 9a, b) and for PTX was $52 \%$ on the same day ( $p \leq 0.05$ versus controls, Fig. $9 \mathrm{a}, \mathrm{b}$ ). Finally, we found that none of the treatments showed any toxicities or side effects.

\section{Discussion}

ATC represents an intrinsically radio- and chemo-resistant tumor type [35]. This resistance may, among others, be due altered expression of key molecules involved in the RAS/ MAPK/ERK and/or PI3K/AKT/mTOR signaling pathways, as well as increased activities of ABC transporters, such as P-gp and BCRP. P-gp exhibits a broad substrate specificity encompassing various chemical structures and biological activities. Most cytostatic anticancer drugs serve as P-gp substrates, such as antacyclines, taxans, vinca alkaloids and epipodofilotoxins [36]. A high BCRP expression is mainly responsible for the resistance of tumors to topoisomerase I or II inhibitors, such as topotecan, irinotecan and doxorubicin [24]. Although data on P-gp and BCRP expression in ATC patients are still scarce [37], the observation that resistance to DOX and PTX may occur after their application has prompted researchers to propose that side populations of resistant cells responsible for tumor regrowth must express P-gp and/or BCRP. Subsequent in vitro and ex vivo observations have confirmed this assumption [38, 39].

Here, we first examined the expression of P-gp and BCRP in a set of primary ATC samples by immunohistochemistry and observed a significant expression of both transporters. According to the immunoreactivity scoring applied, a high P-gp expression was more abundant among the tested samples than a high BCRP expression. Patients with a high P-gp expression score showed a tendency for a reduced survival compared to patients with a low P-gp expression. More significant and conclusive results regarding the association of $\mathrm{ABC}$ transporter expression and ATC patient survival should, however, be obtained using larger patient cohorts.

Secondly, we employed the $8505 \mathrm{C}$ cell line, which is wildtype for NRAS, HRAS, KRAS, PI3KCA and PTEN, but harbors mutations in BRAF and TP53 [40], to sort a minor subpopulation of cells exhibiting a low Rho 123 accumulating capacity. These sorted cells, named Rho-, were found to exhibit increased P-gp and BCRP expression levels, indicating that they possess phenotypic characteristics different from the bulk of parental $8505 \mathrm{C}$ cells. We also found that the Rho- cells are 
A

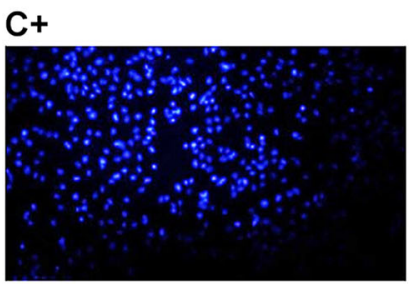

PTX

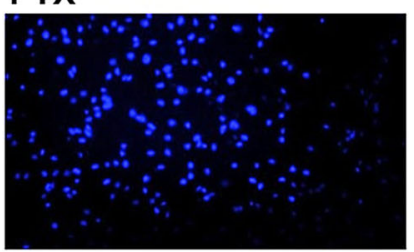

B

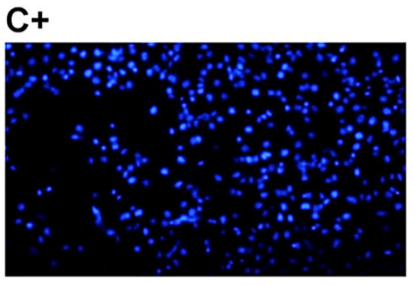

PTX

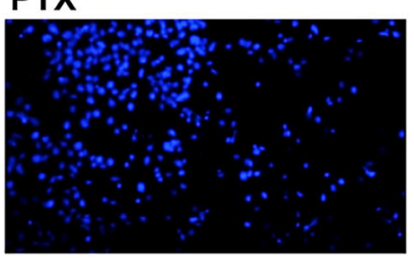

Invasion of $8505 \mathrm{C}$ cells

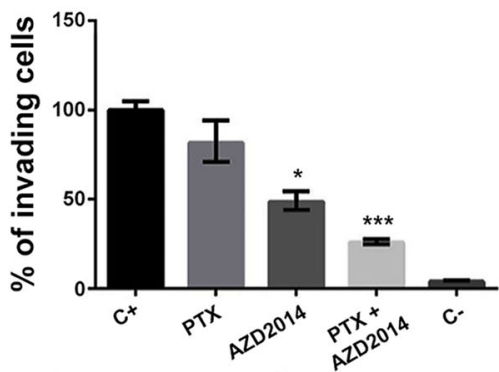

\section{AZD2014}

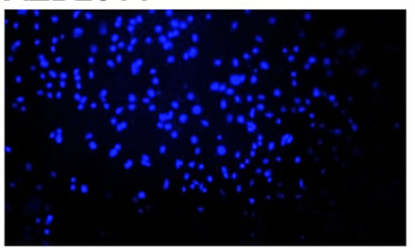

Invasion of Rho- cells

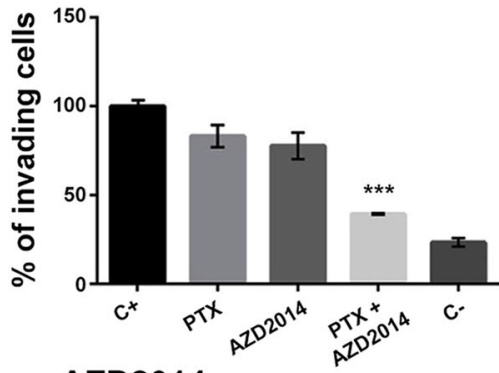

AZD2014

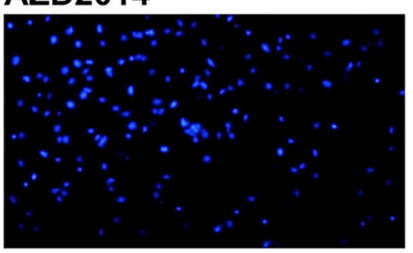

C-

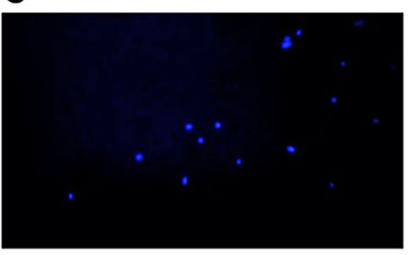

PTX+AZD2014

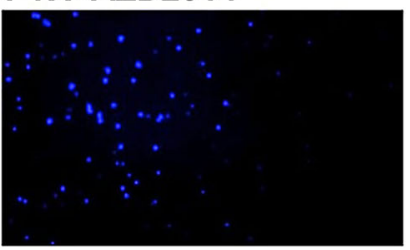

C-

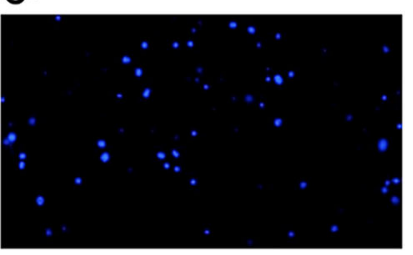

\section{PTX+AZD2014}

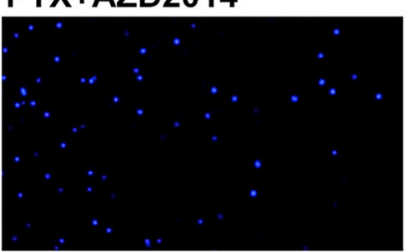

Fig. 8 Potential of single and combined AZD2014 and PTX treatments to suppress invasion through matrigel. (a) $8505 \mathrm{C}$ and (b) Rho- cell invasion through Transwell membranes covered with matrigel. c+ positive control (with FBS as chemoattractant) and c- negative control (without chemoattractant). The respective cells were treated with $10 \mathrm{nM}$ PTX,
$100 \mathrm{nM}$ AZD2014 and their combination. The figures show nuclei (blue color) of cells invaded through matrigel. $* * p \leq 0.01$ and $* * * p \leq 0.001$ : statistically significant differences between treated cells and untreated controls. Three independent experiments were performed $(n=3)$

AZD2014 than its parental 8505C cells, increased expression of P-gp is not required for this induction.

We also assessed the in vitro and in vivo tumorigenic characteristics of the newly isolated Rho- cells and found that, according to spheroid formation assays and tumor growth in NSG mice, the Rho- cells were more tumorigenic than their parental 8505C cells. Drug resistant cancer cells often show increased tumorigenic capacities, and the $\mathrm{ABC}$ transporter overexpression phenotype is considered to represent a cancer stem cell phenotype capable of more readily giving rise to tumors in vivo. Concordantly, it has recently been reported that P-gp overexpressing colon cancer cells, besides being 
Fig. 9 Suppression of tumor growth in vivo. a Growth of $8505 \mathrm{C}$ and Rho- tumors as xenografts in SCID mice treated weekly with $5 \mathrm{mg} / \mathrm{kg}$ PTX, $2.5 \mathrm{mg} / \mathrm{kg}$ AZD2014 and their combination. $* p \leq 0.05$ : statistically significant suppression observed after PTX treatment. ${ }^{*} p \leq 0.05$ : statistically significant suppression observed after AZD2014 treatment. ${ }^{\$} p \leq$ 0.05 : statistically significant suppression observed after combination treatment. $\mathbf{b}$

Treatment efficacy by $\% \mathrm{dT} / \mathrm{dC}$ : values below $42 \%$ represent highly active treatment efficacies according to NCI guidelines
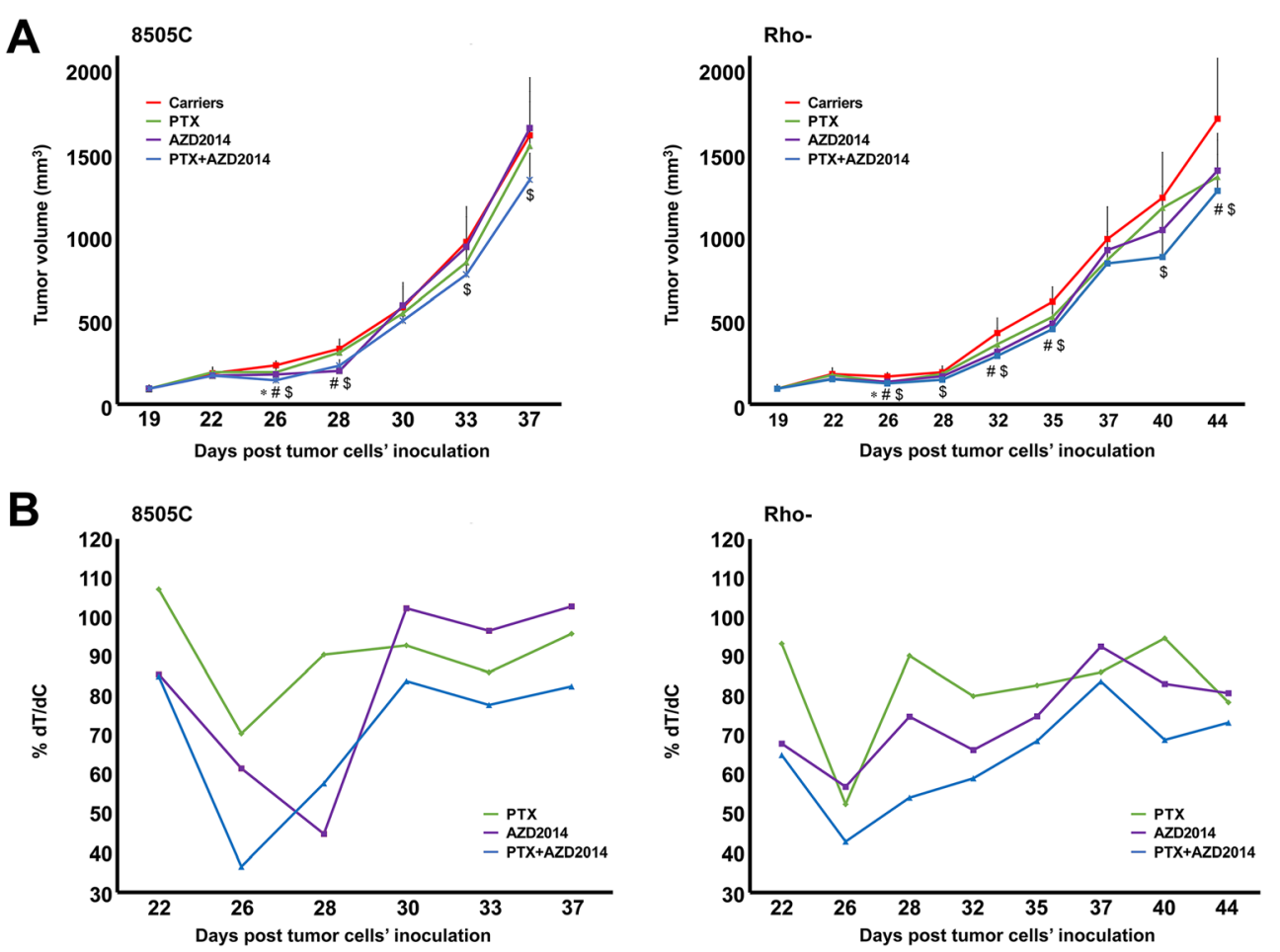

more resistant to chemotherapy and less proliferative, possess a less differentiated phenotype similar to cancer stem cells [42]. We found that the P-gp and BCRP expression levels in Rho- cells did not change during tumor growth in mice. Taken together, we conclude that Rho- cells may serve as a valuable model to assess new therapeutic approaches directed against drug resistant ATC cells.

Next, we used Rho- cells as a model to test the efficacy of simultaneous AZD2014 and PTX treatment. PTX induces cancer cell death by interfering with microtubule assembly and inducing mitotic arrest. It has also been reported that cancer cells may circumvent the effects of PTX by escaping mitotic arrest before cell death or by overexpressing $\mathrm{ABC}$ transporters [43]. In addition, it was recently reported that mTOR inhibition may cause a sensitization of HT-29 colon cancer cells to PTX [44]. Previously, we have similarly shown that combining the mTOR inhibitor AZD2014 with either DOX or PTX significantly increased the sensitivity of ATC cells to these drugs [10]. This synergy with AZD2014 was considerably higher than that obtained with other inhibitors of key molecules involved in the RAS/MAPK/ERK and PI3K/AKT/mTOR signaling pathways, such as PI3K, AKT and RAS [10]. Therefore, we hypothesized that application of AZD2014 might overcome PTX resistance in Rho- cells. Indeed, we found that AZD2014 enhanced the anti-proliferative effect of PTX in both $8505 \mathrm{C}$ and Rho- cells, with a more pronounced synergistic effect in Rho- cells. We also found that this synergistic anti-proliferative effect did not result from cell death but rather from autophagy induction. Comparable results have been reported for other mTOR inhibitors that did not induce cell death, but rather decreased cell proliferation through a reduced expression and activity of cell cycle regulatory proteins [45].

ATC is a notoriously aggressive tumor type that tends to invade surrounding tissue and to metastasize to lymph nodes and distant organs, such as lungs and bones. This invasive and metastatic nature is one of the reasons for its poor prognosis [46]. PI3K/AKT/mTOR activation contributes to metastatic cell movement through activation of Rho GTPases [47], which are involved in cytoskeleton dynamics, cell adhesion and migration and, as such, play a central role in invasion and metastasis [48]. In addition, high mTOR activities and low autophagy levels have been observed during cancer cell migration, while pharmacological inhibition of mTOR was able to attenuate this migration $[49,50]$. Specifically, mTOR inhibition was found to induce cytoskeleton rearrangements, to increase cell-cell contacts and to decrease the activity of Rho GTPases [49]. Based on the observation that AZD2014, besides acting against its target mTOR, may also inhibit pAKT and pS6 kinase [51], we tested whether AZD2014 has the potential to suppress $8505 \mathrm{C}$ and Rho- cell migration and invasion when applied alone or in combination with PTX. We found that the combination of AZD2014 and PTX significantly suppressed cell migration and invasion, while single treatments were less effective. In the 8505C cells AZD2014 exhibited some degree of migration and invasion inhibition that was considerably enhanced by co-treatment with PTX. In the drug resistant Rho- 
cells single treatments had no effect on migration and invasion, while the combination was exceptionally efficient. This synergistic effect may be explained by S6 kinase inhibition [52], and it has indeed been reported that PTX may decrease S6 kinase activity [53]. A role of this kinase has been demonstrated in different types of cell movements, and through activation of matrix metalloproteinases (MMP1, MMP9, MMP10), $\alpha 2$ integrin and Rho GTPases [54]. Hence, we assume that S6 inhibition may underlie the observed decreases in invasive capacities of the ATC cells examined.

In our xenograft studies we found that the combined treatment, as well as single treatments, were not able to prevent tumor growth in both models (8505C and Rho-), although tumor volumes were found to be decreased after the combined application of PTX and AZD2014. According to NCI standards [55], the best therapeutic efficacy of AZD2014 and its combination with PTX (\% dT/ $\mathrm{dC}$ values less than $42 \%$ ) in $8505 \mathrm{C}$ xenografts was observed after two cycles of treatment (at the 26th day post inoculation), while the combined treatment reached $43 \%$ of $\% \mathrm{dT} / \mathrm{dC}$ in Rho- xenografts also at the 26th day post inoculation. These results imply that the combination of AZD2014 and PTX has a potential for ATC treatment, but further investigations with higher AZD2014 doses and/or different treatment schedules (e.g. application twice per week instead of once per week) are warranted to further optimize the capacity of this therapeutic strategy. Recently, A phase I study (TAX-TORC) of AZD2014 plus PTX in advanced solid tumors has shown promising results in squamous non-small cell lung carcinoma (NSCLC) and ovarian carcinoma [56].

In conclusion, we found that the dual mTOR inhibitor AZD2014 is capable of increasing the sensitivity of ATC cells to PTX. The combination of AZD2014 and PTX has the ability to suppress the migration and invasion of ATC cells. Considering the fact that chemo-resistance and invasion are the main causes of a poor ATC prognosis, the proposed combined approach could be beneficial for patients suffering from this particularly aggressive malignancy.

Acknowledgements This study was supported by Grant III41031 from the Ministry of Education, Science and Technological Development, Republic of Serbia. The work was performed within the framework of COST Actions CM1106 - Chemical Approaches to Targeting Drug Resistance in Cancer Stem Cells (the first author was awarded with a STSM grant) and CM1407 - Challenging organic syntheses inspired by nature - from natural products chemistry to drug discovery.

\section{Compliance with ethical standards}

The patient samples were collected and used in the study after obtaining informed consents and approval from the Ethics Committee, in accordance with the ethical standards laid down in the 1964 Declaration of Helsinki. All animals were treated according to the guidelines of the EU and Greek authorities (2010/63/EU directive and Greek PD 56/2013, respectively) governing the use and handling of experimental animals.

Conflict of interest The authors declare that they have no conflict of interest

\section{References}

1. J.L. Pasiekal, Anaplastic thyroid cancer. Curr. Opin. Oncol. 15, 7883 (2003)

2. S. Edge, D.R. Byrd, C.C. Compton, A.G. Fritz, F. Greene, A. Trotti, AJCC Cancer Staging Manual, 7th edn. (Springer, New York, 2010), pp. 1-646

3. C. Are, A.R. Shaha, Anaplastic thyroid carcinoma: Biology, pathogenesis, prognostic factors, and treatment approaches. Ann. Surg. Oncol. 13, 453-464 (2006)

4. R.O. Wein, R.S. Weber, Anaplastic thyroid carcinoma: Palliation or treatment? Curr Opin Otolaryngol. Head. Neck. Surg. 19, 113-118 (2011)

5. R.I. Haddad, W.M. Lydiatt, D.W. Ball, N.L. Busaidy, D. Byrd, G. Callender, P. Dickson, Q.Y. Duh, H. Ehya, M. Haymart, C. Hoh, J.P. Hunt, A. Iagaru, F. Kandeel, P. Kopp, D.M. Lamonica, J.C. McCaffrey, J.F. Moley, L. Parks, C.D. Raeburn, J.A. Ridge, M.D. Ringel, R.P. Scheri, J.P. Shah, R.C. Smallridge, C. Sturgeon, T.N. Wang, L.J. Wirth, K.G. Hoffmann, M. Hughes, Anaplastic tyroid carcinoma, Version 2. 2015. J. Natl. Compr. Canc. Netw. 13, 1140 1150 (2015)

6. N. Smith, C. Nucera, Personalized therapy in patients with anaplastic thyroid cancer: Targeting genetic and epigenetic alterations. J. Clin. Endocrinol. Metab. 100, 35-42 (2015)

7. Z. Liu, P. Hou, M. Ji, H. Guan, K. Studeman, K. Jensen, V. Vasko, A.K. El-Naggar, M. Xing, Highly prevalent genetic alterations in receptor tyrosine kinases and phosphatidylinositol 3-kinase/akt and mitogen-activated protein kinase pathways in anaplastic and follicular thyroid cancers. J. Clin. Endocrinol. Metab. 93, 3106-3116 (2008)

8. M.C. Mendoza, E.E. Er, J. Blenis, The Ras-ERK and PI3K-mTOR pathways: Cross-talk and compensation. Trends. Biochem. Sci. 36, 320-328 (2011)

9. J.A. McCubrey, L.S. Steelman, S.L. Abrams, J.T. Lee, F. Chang, F.E. Bertrand, P.M. Navolanic, D.M. Terrian, R.A. Franklin, A.B. D'Assoro, J.L. Salisbury, M.C. Mazzarino, F. Stivala, M. Libra, Roles of the RAF/MEK/ERK and PI3K/PTEN/AKT pathways in malignant transformation and drug resistance. Adv. Enzym. Regul. 46, 249-279 (2006)

10. Z. Milosevic, M. Pesic, T. Stankovic, J. Dinic, Z. Milovanovic, J. Stojsic, R. Dzodic, N. Tanic, J. Bankovic, Targeting RAS-MAPKERK and PI3K-AKT-mTOR signal transduction pathways to chemosensitize anaplastic thyroid carcinoma. Transl. Res. 164, 411-423 (2014)

11. D.A. Guertin, D.M. Sabatini, Defining the role of mTOR in cancer. Cancer Cell 12, 9-22 (2007)

12. J. Copp, G. Manning, T. Hunter, TORC-specific phosphorylation of mammalian target of rapamycin (mTOR): Phospho-Ser2481 is a marker for intact mTOR signaling complex 2. Cancer Res. 69, 1821-1827 (2009)

13. Y. Alvarado, M.M. Mita, S. Vemulapalli, D. Mahalingam, A.C. Mita, Clinical activity of mammalian target of rapamycin inhibitors in solid tumors. Target. Oncol. 6, 69-94 (2011)

14. S.A. Wander, B.T. Hennessy, J.M. Slingerland, Next-generation mTOR inhibitors in clinical oncology: How pathway complexity informs therapeutic strategy. J. Clin. Invest. 121, 1231-1241 (2011) 
15. M. Hardt, N. Chantaravisoot, F. Tamanoi, Activating mutations of TOR (target of rapamycin). Genes Cells 16, 141-151 (2011)

16. M. Saji, M.D. Ringel, The PI3K-Akt-mTOR pathway in initiation and progression of thyroid tumors. Mol. Cell. Endocrinol. 321, 20 28 (2010)

17. M.S. Petrulea, T.S. Plantinga, J.W. Smit, C.E. Georgescu, R.T. Netea-Maier, PI3K/Akt/mTOR: A promising therapeutic target for non-medullary thyroid carcinoma. Cancer. Treat. Rev. 41, 707-713 (2015)

18. N.N. Bennani, B.R. LaPlant, S.M. Ansell, T.M. Habermann, D.J. Inwards, I.N. Micallef, P.B. Johnston, L.F. Porrata, J.P. Colgan, S.N. Markovic, G.S. Nowakowski, W.R. Macon, C.B. Reeder, J.R. Mikhael, D.W. Northfelt, I.M. Ghobrial, T.E. Witzig, Efficacy of the oral mTORC1 inhibitor everolimus in relapsed or refractory indolent lymphoma. Am. J. Hematol. 92, 448-453 (2017)

19. D.X. Assad, S.T. Elias, A.C. Melo, C.G. Ferreira, G. De Luca Canto, E.N. Guerra, Potential impact of mTOR inhibitors on cervical squamous cell carcinoma: A systematic review. Oncol. Lett. 12, 4107-4116 (2016)

20. R. Zoncu, A. Efeyan, D.M. Sabatini, mTOR: From growth signal integration to cancer, diabetes and ageing. Nat. Rev. Mol. Cell. Biol. 12, 21-35 (2011)

21. K. Yu, L. Toral-Barza, C. Shi, W.G. Zhang, J. Lucas, B. Shor, J. Kim, J. Verheijen, K. Curran, D.J. Malwitz, D.C. Cole, J. Ellingboe, S. Ayral-Kaloustian, T.S. Mansour, J.J. Gibbons, R.T. Abraham, P. Nowak, A. Zask, Biochemical, cellular, and in vivo activity of novel ATP-competitive and selective inhibitors of the mammalian target of rapamycin. Cancer Res. 69, 6232-6240 (2009)

22. T. Powles, M. Wheater, O. Din, T. Geldart, E. Boleti, A. Stockdale, S. Sundar, A. Robinson, I. Ahmed, A. Wimalasingham, W. Burke, S.J. Sarker, S. Hussain, C. Ralph, A randomised phase 2 study of AZD2014 versus Everolimus in patients with VEGF-refractory metastatic clear cell renal Cancer. Eur. Urol. 69, 450-456 (2016)

23. S.M. Guichard, J. Curwen, T. Bihani, C.M. D'Cruz, J.W. Yates, M. Grondine, Z. Howard, B.R. Davies, G. Bigley, T. Klinowska, K.G. Pike, M. Pass, C.M. Chresta, U.M. Polanska, R. McEwen, O. Delpuech, S. Green, S.C. Cosulich, AZD2014, an inhibitor of mTORC1 and mTORC2, is highly effective in ER+ breast Cancer when administered using intermittent or continuous schedules. Mol. Cancer Ther. 14, 2508-2518 (2015)

24. L. Doyle, D.D. Ross, Multidrug resistance mediated by the breast cancer resistance protein BCRP (ABCG2). Oncogene 22, 7340$7358(2003)$

25. R.L. Juliano, V. Ling, A surface glycoprotein modulating drug permeability in Chinese hamster ovary cell mutants. Biochim. Biophys. Acta 455, 152-162 (1976)

26. M.M. Gottesman, V. Ling, The molecular basis of multidrug resistance in cancer: The early years of P-glycoprotein research. FEBS Lett. 580, 998-1009 (2006)

27. R.G. Deeley, C. Westlake, S.P. Cole, Transmembrane transport of endo- and xenobiotics by mammalian ATP-binding cassette multidrug resistance proteins. Physiol. Rev. 86, 849-899 (2006)

28. J.H. Hooijberg, N.A. de Vries, G.J. Kaspers, R. Pieters, G. Jansen, G.J. Peters, Multidrug resistance proteins and folate supplementation: Therapeutic implications for antifolates and other classes of drugs in cancer treatment. Cancer Chemother. Pharmacol. 58, 1-12 (2006)

29. B. Sarkadi, L. Homolya, G. Szakacs, A. Varadi, Human multidrug resistance $\mathrm{ABCB}$ and $\mathrm{ABCG}$ transporters: Participation in a chemoimmunity defense system. Physiol. Rev. 86, 1179-1236 (2006)

30. E.E. Pakos, J.P. Ioannidis, The association of P-glycoprotein with response to chemotherapy and clinical outcome in patients with osteosarcoma. A meta-analysis Cancer 98, 581-589 (2003)
31. A.J. Zurita, J.E. Diestra, E. Condom, X. Garcia Del Muro, G.L. Scheffer, R.J. Scheper, J. Perez, J.R. Germa-Lluch, M.A. Izquierdo, Lung resistance-related protein as a predictor of clinical outcome in advanced testicular germ-cell tumours. Br. J. Cancer 88, 879-886 (2003)

32. T.C. Chou, P. Talalay, Quantitative analysis of dose-effect relationships: The combined effects of multiple drugs or enzyme inhibitors. Adv. Enzym. Regul. 22, 27-55 (1984)

33. W. Kang, O. Nielsen, C. Fenger, G. Leslie, U. Holmskov, K.B. Reid, Induction of DMBT1 expression by reduced ERK activity during a gastric mucosa differentiation-like process and its association with human gastric cancer. Carcinogenesis 26, 1129-1137 (2005)

34. L.G. Mahaira, C. Tsimplouli, N. Sakellaridis, K. Alevizopoulos, C. Demetzos, Z. Han, P. Pantazis, K. Dimas, The labdane diterpene sclareol (labd-14-ene-8, 13-diol) induces apoptosis in human tumor cell lines and suppression of tumor growth in vivo via a p53independent mechanism of action. Eur. J. Pharmacol. 666, 173$182(2011)$

35. G. Nagaiah, A. Hossain, C.J. Mooney, J. Parmentier, S.C. Remick, Anaplastic thyroid cancer: A review of epidemiology, pathogenesis, and treatment. J. Oncol. 2011, 542358 (2011)

36. K.L. Fung, M.M. Gottesman, A synonymous polymorphism in a common MDR1 (ABCB1) haplotype shapes protein function. Biochim. Biophys. Acta 1794, 860-871 (2009)

37. J.Y. Yun, Y.A. Kim, J.Y. Choe, H. Min, K.S. Lee, Y. Jung, S. Oh, J.E. Kim, Expression of cancer stem cell markers is more frequent in anaplastic thyroid carcinoma compared to papillary thyroid carcinoma and is related to adverse clinical outcome. J. Clin. Pathol. 67, 125-133 (2014)

38. X. Zheng, D. Cui, S. Xu, G. Brabant, M. Derwahl, Doxorubicin fails to eradicate cancer stem cells derived from anaplastic thyroid carcinoma cells: Characterization of resistant cells. Int. J. Oncol. 37, 307-315 (2010)

39. V. Carina, G. Zito, G. Pizzolanti, P. Richiusa, A. Criscimanna, V. Rodolico, L. Tomasello, M. Pitrone, W. Arancio, C. Giordano, Multiple pluripotent stem cell markers in human anaplastic thyroid cancer: The putative upstream role of SOX2. Thyroid 23, 829-837 (2013)

40. M. Saiselet, S. Floor, M. Tarabichi, G. Dom, A. Hebrant, W.C. van Staveren, C. Maenhaut, Thyroid cancer cell lines: An overview. Front. Endocrinol. 3, 133 (2012)

41. F. Marcucci, P. Ghezzi, C. Rumio, The role of autophagy in the cross-talk between epithelial-mesenchymal transitioned tumor cells and cancer stem-like cells. Mol. Cancer 16, 3 (2017)

42. U. Schumacher, N. Nehmann, E. Adam, D. Mukthar, I.N. Slotki, H.P. Horny, M.J. Flens, B. Schlegelberger, D. Steinemann, MDR-1overexpression in HT 29 colon cancer cells grown in SCID mice. Acta Histochem. 114, 594-602 (2012)

43. M. Kavallaris, Microtubules and resistance to tubulin-binding agents. Nat. Rev. Cancer 10, 194-204 (2010)

44. H. Zou, L. Li, I. Garcia Carcedo, Z.P. Xu, M. Monteiro, W. Gu, Synergistic inhibition of colon cancer cell growth with nanoemulsion-loaded paclitaxel and PI3K/mTOR dual inhibitor BEZ235 through apoptosis. Int. J. Nanomedicine 11, 1947-1958 (2016)

45. C.J. Guigon, L. Fozzatti, C. Lu, M.C. Willingham, S.Y. Cheng, Inhibition of mTORC1 signaling reduces tumor growth but does not prevent cancer progression in a mouse model of thyroid cancer. Carcinogenesis 31, 1284-1291 (2010)

46. D. Giuffrida, H. Gharib, Anaplastic thyroid carcinoma: Current diagnosis and treatment. Ann. Oncol. 11, 1083-1089 (2000)

47. V. Kolsch, P.G. Charest, R.A. Firtel, The regulation of cell motility and chemotaxis by phospholipid signaling. J. Cell. Sci. 121, 551559 (2008) 
48. F.M. Vega, A.J. Ridley, Rho GTPases in cancer cell biology. FEBS Lett. 582, 2093-2101 (2008)

49. P. Gulhati, K.A. Bowen, J. Liu, P.D. Stevens, P.G. Rychahou, M. Chen, E.Y. Lee, H.L. Weiss, K.L. O'Connor, T. Gao, B.M. Evers, mTORC1 and mTORC2 regulate EMT, motility, and metastasis of colorectal cancer via RhoA and Rac1 signaling pathways. Cancer Res. 71, 3246-3256 (2011)

50. H. Liao, Y. Huang, B. Guo, B. Liang, X. Liu, H. Ou, C. Jiang, X. Li, D. Yang, Dramatic antitumor effects of the dual mTORC1 and mTORC2 inhibitor AZD2014 in hepatocellular carcinoma. Am. J. Cancer Res. 5, 125-139 (2015)

51. K.G. Pike, K. Malagu, M.G. Hummersone, K.A. Menear, H.M. Duggan, S. Gomez, N.M. Martin, L. Ruston, S.L. Pass, M. Pass, Optimization of potent and selective dual mTORC1 and mTORC2 inhibitors: The discovery of AZD8055 and AZD2014. Bioorg. Med. Chem. Lett. 23, 1212-1216 (2013)

52. A. Shafer, C. Zhou, P.A. Gehrig, J.F. Boggess, V.L. Bae-Jump, Rapamycin potentiates the effects of paclitaxel in endometrial cancer cells through inhibition of cell proliferation and induction of apoptosis. Int. J. Cancer 126, 1144-1154 (2010)

53. X.F. Le, W.N. Hittelman, J. Liu, A. McWatters, C. Li, G.B. Mills, R.C. Bast Jr., Paclitaxel induces inactivation of p70 S6 kinase and phosphorylation of Thr421 and Ser424 via multiple signaling pathways in mitosis. Oncogene 22, 484-497 (2003)

54. C.K. Ip, A.S. Wong, Exploiting p70 S6 kinase as a target for ovarian cancer. Expert. Opin. Ther. Targets 16, 619-630 (2012)

55. T. Corbett, L. Polin, P. LoRusso, F. Valeriote, C. Panchapor, S. Pugh, K. White, J. Knight, L. Demchik, J. Jones, L. Jones, L. Lisow, In Vivo Methods for Screening and Preclinical Testing. (Humana Press, 2004), pp. 24

56. Cancer Research UK (2017), Available from: http://www. cancerresearchuk.org/about-cancer/find-a-clinical-trial/a-trial-ofazd2014-with-paclitaxel-for-solid-tumours-tax-torc. Accessed Aug 2017 